This is an Accepted Manuscript of the article Knickmeyer, Doris. "Social factors influencing household waste separation: A literature review on good practices to improve the recycling performance of urban areas." Journal of Cleaner Production (2019): 118605, available online at https://doi.org/10.1016/j.jclepro.2019.118605 @2019. This manuscript version is made available under the CC-BY-NC-ND 4.0 license.

\title{
SOCIAL FACTORS INFLUENCING HOUSEHOLD WASTE SEPARATION: A literature review on good practices to improve the recycling performance of urban areas
}

\author{
Doris Knickmeyer \\ Institute of Environmental Science and Technology (ICTA), Building Z, Carrer de les Columnes, \\ Universitat Autònoma de Barcelona (UAB), 08193, Bellaterra (Cerdanyola del Vallès), Barcelona, \\ Spain
}

\section{d.knickmeyer@web.de}

\section{Introduction}

Moving towards a circular economy, reducing resource consumption and tackling pollution worldwide requires not only the prevention and reduction of waste in the first place, but the adaptation of existing policies and services accompanied by a change in consumer culture and behaviour. The United Nations project that $68 \%$ of the world population will live in urban areas by 2050 (UN DESA, 2018). As the population grows globally, rural populations are migrating to cities (UN DESA, 2017). According to the Global Waste Management Outlook, the rapid improvement of standard of living and income - especially in developing and industrializing countries - coincides with increased resource consumption and the generation of more waste. As population density, urbanization and industrialization continue to increase, so too are global urban waste quantities (which are already estimated to be at 2 billion tons of municipal solid waste per year) (Wilson, 2015). Municipal solid waste management systems (MSWMS) are put under tremendous pressure and the World Bank's Urban Development department warns that communal budgets will be exhausted intrinsically (Hoornweg and Bhada-Tata, 2012).

The growth of urban wastes is a critical global issue because it poses a threat to human health and the environment if not properly dealt with. Concerns include emissions coming from waste decomposition in landfill sites and the simple fact that landfills are already full. China's decision to ban the import of foreign garbage served as a 'global recycling wakeup call' ${ }^{1}$. The United Nations Environment Programme regards waste management (WM) as a 'basic human right'. Addressing more than half of the sustainable development goals ${ }^{2}$, WM promises significant greenhouse gas reductions and thus has the highest political priority (Wilson, 2015). As stated in the World Economic and Social Survey 2013, the reduction of waste production, improvement of waste collection and recycling systems are amongst the most pressing challenges of our time, and investments in strategies are needed in most cities worldwide (UN DESA, 2013). To address our resource problem the European Commission released the Waste Framework Directive (EC, 2008) and the Circular Economy package (EC, 2015). The objectives include recycling 50\% of urban waste by 2020 and reusing 'waste' as a resource whenever possible, accompanied by an overall reduction of waste. As urban residents generate large quantities of municipal wastes, their participation in the MSWMS by pre-sorting common household waste streams at source is critical to reduce the amount of contamination that could ruin batches of recycled material ${ }^{3}$. It is fundamental for improving the overall recycling performance and enabling the maximum recovery of useful resources (Varotto and Spagnolli, 2017). Moreover, requirements for quality of recyclate are becoming more strict and the 
rejection of loads due to ineffective recycling behaviour can entail large financial impacts (Jesson et al., 2014). Efficient recycling systems depend upon how well the public participates (Thomas, 2001). Yet, recycling rates from densely populated urban cities are under-performing in comparison with less populated areas (Miafodzyeva and Brandt, 2013). Thus, local decision-makers bear a great responsibility as they determine whether the common global WM goals will be accomplished. In the process of establishing and improving well-performing MSWMS the understanding of fundamental social factors to influence public behaviour is commonly underestimated but of utmost importance.

In scientific research also, this specific topic does not receive the necessary attention and few give weight to it. Research on social dimensions of MSWMS is absolutely underrepresented - out of the total number of publications on 'municipal solid waste' they had a share of $0,69 \%$ in 2014 (Ma and Hipel, 2016). Although more attention is being paid to social dimensions of MSWMS recently, the majority of these results are geographically restricted. To the best knowledge of the author, the most recent synthesizing meta-analyses of literature dealing with the specific topic of recycling behaviour amongst householders and summarizing its determinants are by (Miafodzyeva \& Brandt, 2013) and - with a special focus on psychology - (Varotto \& Spagnolli, 2017). Further, a systematic literature review by Ma \& Hipel (2016) globally detects issues in the social dimensions of MSWMS with a focus on vulnerability, public participation, public attitude, behaviour and policy. A summary of literature that is going beyond this scope and focuses specifically on the current challenges of urban areas while delivering solution-oriented results is non-existent.

Based on the above-mentioned scientific research and outlined gaps, this paper aims to deliver a solution-oriented approach. Compiling theory and good practices from cities globally, this article intends to achieve a greater depth of understanding and illustrate the importance of the relevant social factors. Moreover, the research aspires to provide practical insights as a means of orientation and inspiration to develop the right strategies for specific local contexts. Therefore, the paper is explicitly not limited to western-developed countries and comes from the point of view that WM is a global issue demanding collaboration and cooperation. In this context, the main objectives guiding this research are:

(1) Determining the social factors influencing household waste separation behaviour,

(2) Presenting recommendations and good practices from cities all over the world to improve this behaviour and

(3) Highlighting those factors with the potential to improve recycling in densely populated areas.

The structure of the article follows accordingly. Section 2 describes the research material and methods. Section 3 gives a comprehensive theoretical overview of social factors influencing household waste separation behaviour. The following section 4 is a special chapter on planning behaviour change, in order to support practitioners and to incorporate selected recommendations. In section 5 good practices to improve the recycling performance of urban areas are presented. Building on this, section 6 is dealing with the problematic of compact cities. Finally, section 7 presents the conclusions and outlook. This framework offers relevant support for WM practitioners and policy makers from different backgrounds to design future strategies and interventions to improve their recycling rates by motivating household waste separation behaviour.

\section{Material and methods}

The method used to conduct this paper was an exploratory literature review. Given the urgency of the issue, this approach has been favored over a more systematic statistical analysis one in order to open up a new perspective on the topic and focus on findings that pave the way for workable solutions and further research. The databases ScienceDirect, as the widest search engine for peerreviewed scientific literature, and ResearchGate, for its approach to connect scientists and make research open, were chosen to be searched. The keywords used - household, recycling, social, waste 
separation and behaviour - were directly derived from the guiding research objectives. This search enabled to identify the most relevant and recent systematic literature reviews and meta-analyses in the field (Ma and Hipel, 2016; Miafodzyeva and Brandt, 2013; Varotto and Spagnolli, 2017). Hence, the existing literature is taken into account and served as a content basis for the conceptual structure of this literature review, reflected in the table of contents. Based on that, the search for scientific as well as grey literature was then expanded with more specific keywords - such as convenience, norms, moral, attitude, habit and trust in section 3, education, community, communication, incentives and rewards in section 5 and compact and high-density in section 6 . These keywords have been chosen because they proved to be promising success factors in both the reviewed scientific literature as well as practical reports from waste management experts. Furthermore, synonyms and the reference lists of reviewed papers were scanned to find more relevant literature. To answer the first research objective, only peer-reviewed scientific literature has been considered. In order to find evidence on good practices from cities and high-density population areas for the second and third research objective, the search has been expanded to the common search engines Google and Ecosia. Regarding their practical relevance, findings from grey literature and less academic sources have been explicitly searched for. Among other sources, working papers by nongovernmental organizations, newspaper and online magazine articles and blog articles available online contributed significantly to the results. To investigate which cities perform in an exemplary way, the recycling rates compared by Greenfield (2016) have been traced and city administration websites were consulted. Additionally, online available reports on waste management and recycling were reviewed. The most relevant reports providing in-depth insights on good practices were:

- "Barriers to Recycling: A review of evidence since 2008", published by the Waste and Resources Action Programme (WRAP, a UK Charity);

- the "Global Waste Management Outlook", published by the United Nations Environment Programme;

- "Best Environmental Management Practice for the Waste Management Sector", published by the Circular Economy and Industrial Leadership Unit of the Joint Research Centre, the European Commission's science and knowledge service;

- "Assessment of separate collection schemes in the $\mathbf{2 8}$ capitals of the EU", a final report for the European Commission issued by BiPRO and the Copenhagen Resource Institute.

Papers were preferably selected if they provided insights on adaptation to local conditions and innovation, while studies which did not contribute sufficient information on waste separation behaviour were excluded. In this respect, the selection of papers was not geographically restricted in order to produce results of global relevance. The selected papers originate from 25 different countries. However, it must be mentioned here that - presumably partly due to the linguistic restriction to English - the selected papers mainly originated in Western countries. The largest numbers of publications come from the UK (27), the United States (22) and Sweden (9). Whilst publications from Africa are underrepresented, no South American scientific publications were considered (see Fig. 1). Except for fundamental theory, publications older than the year 1999 were not considered. The time frame of the past 20 years was chosen in order to present findings which respond to current social developments - thus being most relevant to become the basis for further research. Papers published later than May 2018 have not been taken into account for this review. A final inventory was made of in total 166 references, of which 57 online references are listed in a separate bibliography (and excluded from Figures 1 and 2). From the remaining 109 references, 76 can be qualified as scientific publications - of which 65 have been published in scientific journals. The most cited journals are Waste Management (13x), Resources, Conservation and Recycling (13x) and Environment and Behaviour $(5 \mathrm{x})$. Furthermore, 29 reports are included in the literature review. The distribution of papers by year from 1971 to 2018 is presented in Fig.2. The majority of the selected 
papers were published in the last decade (69x), less than a third (31x) was published in the period 1999-2008 (Fig.2). The 4 sources concerning laws were also excluded from Fig. 2. Table 1 is giving an overview on the types of all used documents and the number of documents per category.

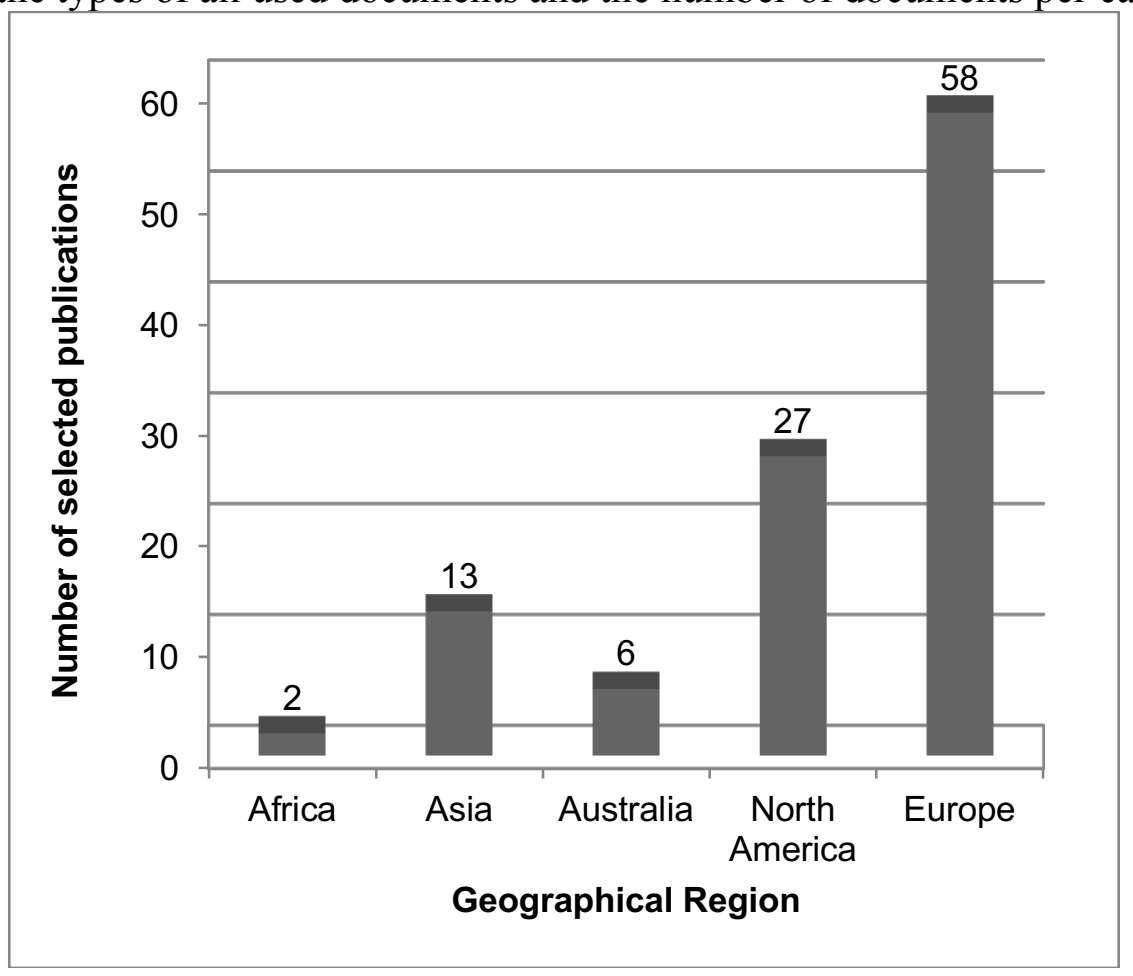

Fig.1. The distribution of the selected publications per geographical region.

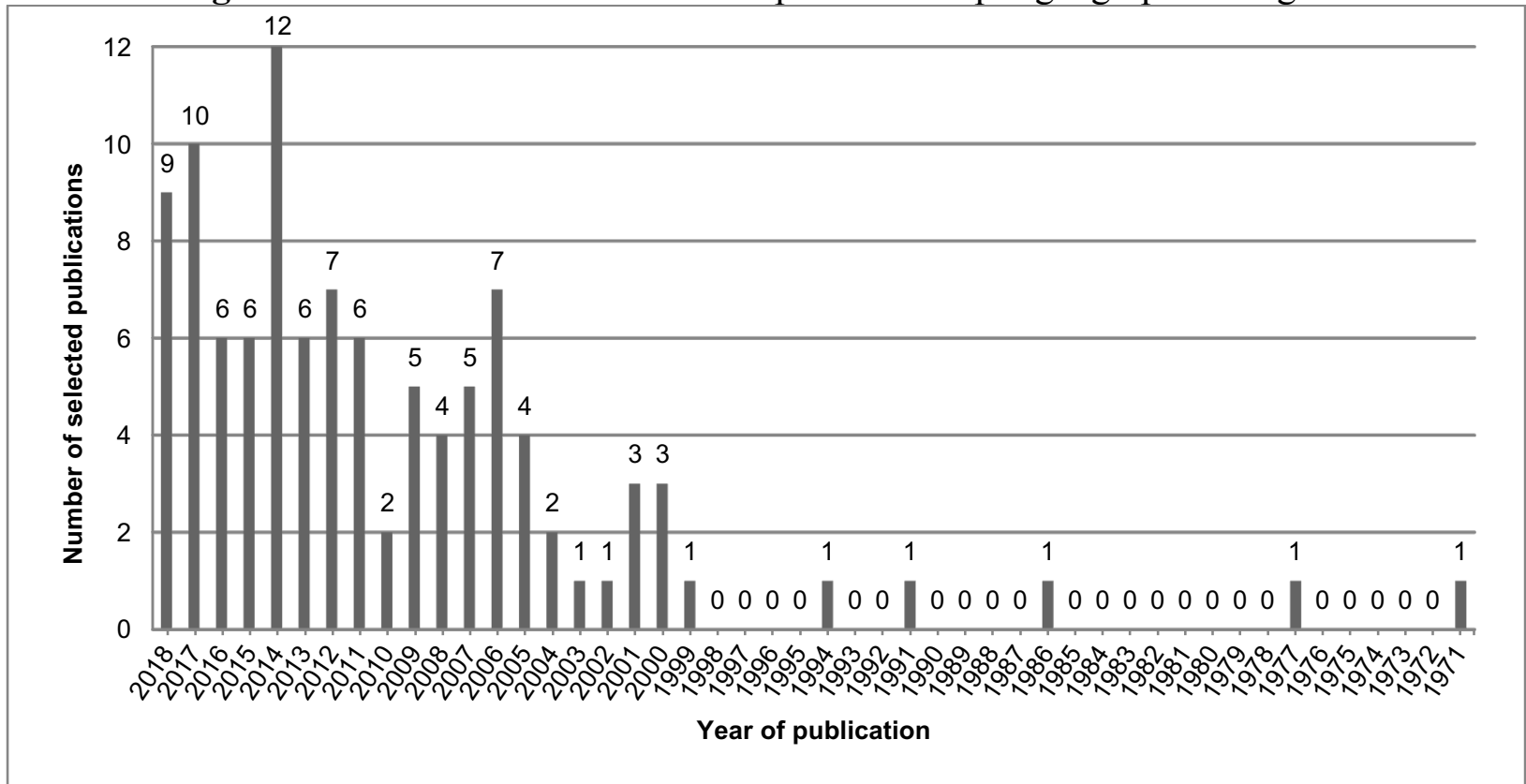

Fig. 2. The distribution of the selected publications per year (1971-2018).

Table 1. Types and number of all documents used.

Number of documents

Scientific journal articles

Scientific publications, books, presentations

Reports, case studies, project reviews

Newspaper/Online magazine/News website arti-

cles

Press release, statement, plan, working paper 
Website passim, blog article, broadcast, documentary

Policy, law, juridicial paper

\section{Social factors influencing household waste separation behaviour}

To ensure the efficiency of MSWMS and achieve higher recycling rates, active household participation is indispensable. Their contribution includes the correct separation of recyclables at home, eventual cleaning, storing and disposing of the closest municipal waste containers. In synergy with the given local infrastructure, legal conditions and interaction of WM agents (administration, packaging manufacturers, businesses, households and waste managers), numerous social factors influence recycling behaviour, but usually receive less attention when it comes to the design of MSWMS.

The capture rates of recyclates vary significantly between fractions of waste, cities and neighbourhoods and so do the individual and households waste separation behaviours (Klöckner and Oppedal, 2011). Obviously there is not 'one applicable system that serves them all' - reflected in the differences of MSWMS implemented in different areas. The more the MSWMS corresponds to local conditions, the more efficient it is. To personalize the content, it is fundamental to connect the design of the action plan with a deeper knowledge of the system users' characteristics (Varotto and Spagnolli, 2017). Here, social factors are defined as all influences that affect an individual's or group's behaviour (Whishaw et al., 2006). This definition includes a broad range of factors, which cannot all be included in this review. The literature offers contradictory evidence regarding the correlation of several social factors with recycling behaviour and their relevance depends on the different local contexts (Miafodzyeva and Brandt, 2013). Therefore, the aim of this review is not to discuss all social factors in detail but to give an overview of existing ones and based on those present good practices. However, one has to be aware of the interdependence of all factors: it is the combination of a set of different factors that determines household waste separation behaviour.

\subsection{Demographic characteristics}

As highlighted before, it is obligatory to examine who has to interact with the given recycling system: the user. Recycling behaviour and related barriers vary by socio-demography; therefore the MSWMS ought to be adjusted to the characteristics of its targeted social groups.

Links between household waste separation behaviour and a variety of individual socio-demographic attributes have been previously studied (see Table 2):

Table 2. Socio-demographic characteristics and household waste separation.

\begin{tabular}{ll}
\hline Socio-demographic attributes & Linked to recycling behaviour in... \\
\hline Age & \\
Income & \\
Education level & \\
Gender & \\
Dwelling Type & Miafodzyeva and Brandt (2013) \\
Family size & \\
Presence of emigrants & \\
Population Density & \\
Political allegiance & \\
Religious Identity & \\
Ethnicity
\end{tabular}



Household Type
Household size
Employment Status
Political beliefs
Becker (2014)
Belonging to cultural group
Presence of children in household Vicente and Reis (2008)
Marital status
Tsaur (2014)
Social class
Iyer and Kashyap (2007)

The effects of socio-demographic variables on recycling rates and their effects on factors that influence recycling behaviour were reviewed profoundly by Becker (2014).

\subsection{Psychological factors}

Further various external and internal socio-psychological variables determine recycling behaviour. Several theoretical frameworks have been developed over the last decades by social psychologists to investigate, model and predict recycling behaviour in relation with its determinants. The following section provides an overview of the main findings and theories.

\subsubsection{Perceived convenience and effort}

One of the most important factors to increase household waste separation behaviour is convenience (Ando and Gosselin, 2005; Barr, 2007; Bernstad, 2014; Miafodzyeva and Brandt, 2013; Schwab et al., 2014). The perception of convenience depends on the individual who is desired to participate in the sorting system. In short: the easier it is to understand and use the system, the more likely it is to be used and vice versa (perceived difficulty results in inconvenience).

Although some may not consider external factors (referred to as situational-contextual, technological or organizational) as socio-psychological, because they are related to the infrastructure and service provision, they are of significant importance in the behavioural context. It appears that they influence the internal factors (Tonglet et al., 2004). In fact, lack of necessary infrastructure can be one of the most important barriers for households to participate in recycling activities (Timlett and Williams, 2009). Even slight changes enhancing convenience can substantially impact behaviour ${ }^{4}$. For source-separation it is stressed that these adjustments must happen inside the household (Bernstad et al., 2013).

The following variables bear the potential to influence convenience positively and can be modified by the local MSWMS but also the household itself (Miafodzyeva and Brandt, 2013; Thomas and Sharp, 2013; Becker, 2014; Varotto and Spagnolli, 2017):

- Short distance and strategic location of collection points for recyclables

- Ease of access and availability of bins

- Appropriate storage space at the household

- Availability of curb-side collection

- High frequency of collection

- Clean appearance of the recycling site

- Smart visual design of collection points (colour, shape, capacity) 
Perceived effort, particularly the time factor, is also linked to convenience (Miafodzyeva and Brandt, 2013).

\subsubsection{State of knowledge and information}

As Barr pinpoints, "knowledge for action is a significant prerequisite for behaving in an appropriate manner and would be a significant barrier to action if levels were low" (2007). He refers to abstract and concrete knowledge - i.e. general awareness of environmental problems and knowing the specific local recycling services. With regard to the situational variables described in 3.2.1, the latter is crucial (Barr, 2007). The continuing change of MSWMS (e.g. specification of wanted/unwanted materials) and population mobility pose learning barriers. In combination with varying systems in different areas and buildings, recycling appears more complex to some residents (Jesson et al., 2014). While understanding the classification is complicated for some people in general (Tsaur, 2014), new material-mixes and multi-component packaging further complicate the learning of how to dispose them properly and risk the creation of ever more confusion ${ }^{5}$. Confusing recycling logos on packaging and a poor understanding of waste treatment activities (people do not understand the value) exacerbate knowledge barriers (Jesson et al., 2014). This may be particularly problematic for growing numbers of 'new immigrants', as they are not initially familiar with local (recycling) regulations or potentially even the language (Miafodzyeva and Brandt, 2013).

\subsubsection{Social Norms}

Fundamental for the desired conduct of household waste separation is the intention to do so. Based on the frequently applied Theory of Planned Behaviour (TPB) by Ajzen (1991), the intention to recycle can be predicted by positive attitude towards recycling, social norms* representing the expectations of relevant people ("social pressure") and perceived behavioural control, which is the feeling of being able to perform the intended recycling behaviour (Klöckner and Oppedal, 2011; Wan et al., 2017). Social norms are determined by local culture and context (Becker, 2014). They control behaviour without legal enforcement (Kessler and Fritsche, 2018) - adherence is rewarded with societal approval (Wan et al., 2017).

Applied to recycling, the influence of others (e.g. family, neighbours, friends) offer guidance and can create more positive intentions to recycle and enhance the consequent action - especially in places with a high visibility of behaviour (Barr et al., 2001). In consonance with Bandura's social learning theory, proposing that in the social learning system new patterns of behaviour can be acquired through direct experience or by observing the behaviour of others (Bandura, 1971), parental behaviour was found to impact the children's subjective norms about recycling (Matthies et al., 2012). Thomas and Sharp (2013) suggest that the 'social pressure' arising from the knowledge that others recycle, is more powerful than the one created by other people having the expectation that one should recycle. However, it appears that in well-established recycling schemes social pressure is not significantly correlated to recycling (Miafodzyeva and Brandt, 2013).

\subsubsection{Moral norms}

Additionally internal personal norms motivate household waste separation behaviour and intention (Klöckner and Oppedal, 2011; Miafodzyeva and Brandt, 2013). It appears that personal or moral norms internalize social norms over time (Schwartz, 1977). In comparison to social norms, which are executed by expressed (dis-) approval from others, moral norms are self-enforced (Hage et al., 2009). Following the norm-activation model, altruistic behaviour is mainly driven by feelings of moral obligation to act (Schwartz, 1977). On this basis, "people might develop a feeling of moral responsibility to recycle, if they are aware of the negative consequences of not recycling, if they are aware that their behaviour has a significant impact on the waste problem, if they feel capable of

\footnotetext{
'Synonymously used for 'subjective norms'.
} 
recycling, and if they finally experience the expectation of other people they value to participate in the recycling program" (Klöckner and Oppedal, 2011). Generally residents will sort wastes if they feel a personal responsibility to do so (Miafodzyeva and Brandt, 2013), which, when acknowledged, can be viewed as civic duty (Xu et al., 2016). Moral concerns may even lower the perceived 'costs' for carrying out recycling (Berglund, 2006). Ultimately Thomas and Sharp point out that if the expectation to recycle is included in the personal norms, the individual will identify as being a recycler (2013).

\subsubsection{Attitude and environmental concern}

Attitude towards recycling and general environmental concern significantly influence recycling behaviour and willingness to recycle (Miafodzyeva and Brandt, 2013; Wan et al., 2017). Based on the TPB, Wan et al. (2017) define "experiential attitude is an individual's affective feelings toward behavior (e.g., recycling is good behavior); whereas instrumental attitude refers to an individual's evaluation of behavior's outcomes (e.g., recycling could reduce landfill burden)." Pro-recycling attitudes are found to be the strongest motivator to recycle, influenced by "having appropriate opportunities, facilities and knowledge" and "by not being physically prevented to recycle (time, space, inconvenience)" (Tonglet et al., 2004).

Acknowledging the complexity of behaviour as "a function of the organism and its environment", the Attitude-Behaviour-Context-Theory was developed by Stern (2000) and states that the dependence of behaviours on attitude decreases with difficulty, time-effort and costs unless the context encourages it (such as reward for or requirement of the behaviour). Applied to recycling, the external structural conditions were found to impact the attitude-behaviour-relationship (Ölander and Thøgersen, 2005). Attitudinal barriers to recycling can be beliefs (no environmental/social benefits, no personal reward for efforts), common misconceptions and concerns (regarding food waste e.g. hygiene and smell) (Jesson et al., 2014).

\subsubsection{Recycling habit}

As a behaviour that is carried out on a daily basis under similar conditions, recycling has the potential to turn into habitual behaviour (Klöckner and Oppedal, 2011; Wood et al., 2002). Turning the established household pattern of using a single bin into the "automatic" sorting of waste into different containers (Timlett and Williams, 2009) requires strong internal motivation and is affected by attitude and social norms (Li et al., 2017). Consideration of each step in the recycling process (e.g. sorting, washing, storing, disposal) is recommended to understand it (Knussen and Yule, 2008). The frequency of past behaviours is important, but also is a stable context - constant awareness of action is not necessary (Thomas and Sharp, 2013). The conceptual framework of the Waste and Resources Action Programme in the UK refers to the 'concept of recycling competence', according to which the ideal state of habitual optimum household recycling behaviour is developed by a learning cycle in which people "move from a state of unconscious incompetence [not aware, don't care], through conscious incompetence (recognition of the need to change), to conscious competence (learning to be better) and finally to unconscious competence [embedded systematic routine]" (Jesson et al., 2014). Thomas and Sharp (2013) add that for non-recyclers a 'disruption' is needed, e.g. a change of situation or routine, enabling to revaluate the behaviour. On the other hand these changes form an obstacle for people already having established a habit of recycling (3.2.2) (Jesson et al., 2014). Lack of recycling habit can in turn impact the intention to recycle, independent of past recycling behaviour (Knussen and Yule, 2008).

\subsubsection{System trust and community}

Another driver of recycling behaviour is the household's system trust in the local authority and the recycling program (Loan et al., 2017). System or institutional trust is "created and sustained by the continual, ongoing, and confirmatory experience of a social system's functioning" (Rompf, 2014). Residents with good relationships with the local government are more receptive to the recycling 
requirements (Jesson et al., 2014) and shown to perform better (Xu et al., 2016). Commitment is undermined by mistrust. People's relationship with place and the local neighbourhood is also significant. As highlighted before, population mobility in big cities is increasing and so does the percentage of private renters and short-to-medium term tenants. These people often lack a direct service relationship with the local authority (or don't even know who that is), which represents another challenge for improving recycling behaviour (Jesson et al., 2014). Additionally, 'sense of community', referring to the level of social interaction, is regarded as increasingly important (Miafodzyeva and Brandt, 2013; Tonglet et al., 2004).

\subsection{Economic factors}

Moreover it is suggested that economic factors - perceived convenience and financial costs strongly influence household recycling behaviour (Jenkins et al., 2003). People are said to be primarily utility maximizers motivated by costs and benefits (Saphores et al., 2006). Rompf (2014) applied the rational choice theory, according to which alternatives are evaluated in order to best satisfy preferences, to the cost-benefit structure of recycling: "an actor engages in recycling and waste separation only if the expected utility of recycling, minus the costs associated with it, exceeded that of conventional waste disposal." Yau (2012) also states that rational individuals will not sort waste for "little or no economic gain". This "feasibility' of waste separation for the household is mainly reliant on the variables presented in 3.2.1. Lower socio-economic groups tend to spend less effort on recycling activities due to the simple fact that they have more pressing needs. On the other hand, financial incentives may be an effective driver for low-income-households, e.g. benefiting from selling recyclables: it depends on the right 'stimulus' (Martin et al., 2006). Another related economic factor is the households' willingness to pay for the recycling service (Saphores et al., 2006; Vassanadumrongdee and Kittipongvises, 2018).

\subsection{Political background}

Laws and regulations are influential external factors that increase the pressure on people to recycle (Iyer and Kashyap, 2007) and can influence moral norms (Hage et al., 2009; Schwartz, 1977). While in some areas the acceptance of legal norms is the most common reason for recycling (Miafodzyeva, 2012), they appear less influential in others (Hage et al., 2009). The need for further research was highlighted by Miafodzyeva and Brandt (2013).

\section{Planning behaviour change}

Waste practitioners and policy makers in cities across the globe are facing the challenge of designing strategies and behaviour interventions to improve the recycling performance of their systems and recover the maximum amount of resources. Before presenting good practices, some preliminary considerations regarding the planning process will be examined in order to support the utility of this paper.

\subsection{Team constitution and stakeholder consultation}

Firstly, an integrated approach is required to achieve sustainable WM. As a best practice public engagement is recommended: all stakeholders having a direct interest in the outcome of policy decisions should have the chance to shape them (Defra, 2005a, 2005b; Garnett and Cooper, 2014). This principle of 'user inclusivity' (UN-HABITAT, 2010) refers to the active involvement and participation of all system users - waste processors (formal and informal recyclers), waste generators (households, industries and agriculture) and government institutions (regulators, waste managers and urban planners) (Kurian, 2006).

Principally, local authorities need to realize the potential of inclusive decision processes: being open to public input and considering a variety of viewpoints enables decisions based upon local knowledge and include different interests (e.g. regarding relevant risks) (Garnett and Cooper, 
2014). In turn, the consultation makes the public feel ownership for the WM programmes (Wilson, 2015). The creation of an effective dialogue builds trust and prevents problems, particularly in 'hard to reach communities' (Garnett and Cooper, 2014). For the evaluation of several 'what-if' scenarios by stakeholders an agent-based simulation framework for collaborative decision making has been developed (Meng et al., 2016; Shi et al., 2014).

The diversity of presented factors makes it recommendable to recruit specialist expertise (Li et al., 2017). This may involve academics who specialise in the application of behaviour change theory in the waste sector, NGOs and community groups (Brook Lyndhurst, 2007). The Zero Waste International Alliance suggests the establishment of a "Zero Waste Advisory Board". Specially trained "municipal environment \& waste consultants" are stated as the 'backbone' of improving separate collection in Austria (R4R, 2014a). To transform policy making and change behaviour in ways that serve both individuals and society, some governments successfully involve a "Behavioural Insights Team" (also called 'Nudge Unit'*6), consisting of psychologists and economists ${ }^{7,8}$. Notably, Zero Waste South Australia, a specially created government body for good resource management, drives forward recycling with its revenue stream linked to a landfill tax - for every dollar charged, 50 cents go to ZWSA initiatives (UN-HABITAT, 2010).

\subsection{Preliminary investigations and monitoring}

When it comes to improving recycling behaviour, many honour the performance of Scandinavian countries. It is appropriate here to mention that Sweden addressed waste issues very early on, starting studies in 1969 and special programs for research and development in 1974 (Miliute and Plepys, 2009). Although comprehensive preliminary research is considered to require high expenditures of time and costs, it is a prerequisite to reveal the determinants and barriers of household recycling behaviour in the context of its targeted areas. Careful analysis allows tailoring the interventions to the specific needs of their audience and making them more convincing (Varotto and Spagnolli, 2017). In community-based social marketing, consumer research and attention to detail appear to be successful tools (McKenzie-Mohr, 2000). To achieve social change the use of marketing theory, skills and practices is key: recycling behaviour is considered being the product that has to be 'sold' to the 'consumer'-households and researched likewise (Shrum et al., 1994). The likewise segmentation of households according to their attitudes towards recycling (just as consumer grouping) serves as a base for a social marketing plan (Vicente and Reis, 2007).

To better understand the situational context for behaviour when planning interventions to maximize recycling, the ISB-model (infrastructure, service and behaviour) was developed for waste practitioners (Timlett and Williams, 2011). Timlett and Williams' (2009) recycling behaviour typology grouped into 'sustained recycler', 'non-recycler', 'stopped recycler' and 'new recycler' may also be useful. Investigation into the reasons why people do not, or seldom recycle allow householders who do not (wholly) participate in MSWMS to be specifically targeted (Martin et al., 2006). Further, the use of a geo-demographic segmentation tool at local neighbourhood level is suggested to aid selection of the focus areas (Jesson et al., 2014).

In fact, many MSWMS failures are caused by lack of preliminary investigation and cannot be retraced due to missing monitoring data (Yau, 2012). Moreover, official statistics may not display the actual situation, as households are in a constant 'state of flux' (Timlett and Williams, 2009). Authorities are urged to provide the means for systematically monitoring and reporting behaviour change initiatives in order to identify measures of costs and outcomes (Seyring et al., 2015; Southerton et al., 2011; Wilson, 2015).

\footnotetext{
*The "nudge" theory draws on behavioural economics. American sociologists Richard Thaler and Cass Sunstein describe it as "any aspect of the choice architecture that alters people's behavior in a predictable way without forbidding any options or significantly changing their economic incentives. To count as a mere nudge, the intervention must be easy and cheap to avoid. Nudges are not mandates."
} 


\section{Good practices to improve the recycling performance of urban households}

The social factors discussed previously tend to occur together and jointly contribute to the household recycling performance. To improve, they need to be triggered in synthesis. In the following sections practical recommendations from cities worldwide will be reviewed. The aim is not to present solutions that are applicable everywhere, but to draw attention to the possible ways in which each might improve recycling in practice. As stated in an international review of behaviour change initiatives, attempts to transfer and replicate presented initiatives need to be sensitive to local factors. It is beneficial to seek advice from those involved in their implementation and to exchange knowledge and facilitate learning opportunities globally (Southerton et al., 2011). For practitioners it is suggested to take a closer look at successful cities of comparable size. The International Recycling Rate Comparison Project suggests, there is a problematic lack of data consistency across reported recycling rates of major cities worldwide, which makes it difficult to make reasonable statements when comparing them (Greenfield, 2016). For example, many cities include household waste in their municipal solid waste recycling rate. For the development of this paper the revised rates of the project report were useful.

The UK Department for Environment, Food and Rural Affairs (Defra) recognized an overview of factors as necessary to trigger and sustain change in public behaviour: enablers (removal of barriers and provision of infrastructure, education, information), encouragement (taxes, penalties, rewards, social pressure), engagement (communication, community involvement) and exemplification (consistent policies, leading by example), (Defra, 2006). Varotto and Spagnolli (2017) give an overview on more than 50 studies of intervention strategies and their effectiveness. Obviously, a "mix" of instruments and measures is the key to high recycling performances (R4R, 2014a; Seyring et al., 2015).

\subsection{Consistent laws and policies}

The legal requirement of household recycling in the cities with the highest reported rates varies significantly. Referring to Singapore, "[...] In most cases people do not recycle simply because they are not required to do so," said Tong Yen Wah, co-director of the Energy and Environmental Sustainability Solutions for Megacities program at the NUS Environmental Research Institute ${ }^{9}$. In a report for the European Commission the legal transpositions of separate collection schemes in the 28 EU capitals were reviewed. Regarding the setting of legislation, the introduction of mandatory separate collection systems for certain municipal waste fractions (waste paper, packaging, bio-waste) was recommended (Seyring et al., 2015). Waste separation at the household level needs to become part of a new WM policy or bye-law to enhance reuse (Ekere et al., 2009). In Germany, which has a long legal recycling history, the so-called circular economy law (KrWG) obliges private households to separate their waste since 2015 with different regulations at the local level. In the U.S., Woodbury (New Jersey) became the first city to mandate recycling and promoted a curb-side pickup program. The residents reacted by throwing trash on the lawn of then-mayor Don Sanderson, but within three months the city reached $85 \%$ compliance $^{10}$. As another 'recycling leader' worldwide, San Francisco adopted a Zero Waste Strategy - aiming to "send zero waste to landfill" by 2020 (SF Environment, 2003). The local municipal "Mandatory Recycling and Composting Ordinance" was passed in 2009, requiring all residents to separate their recyclables at source (SF Environment, 2009).

Supported by organizations such as Zero Waste Europe (ZWE) ${ }^{11}$ and the Zero Waste International Alliance ${ }^{12}$, 'zero waste' is presented as a holistic alternative solution for MSWMS ${ }^{13}$ (Connett, 2013). Cities worldwide (such as Adelaide, Vancouver, Barcelona) have included this aspirational goal in their legislation and strategies to tackle waste problems - working towards the sustainable development goals, optimum recycling and resource recovery simultaneously (Zaman, 2015). Several case studies conducted by ZWE prove the effectiveness of the policies in terms of boosting recycling and stimulating impressive rates of waste reduction (Oblad, 2018; Simon, 2018). Policies 
can set the base for social norms by increasing the visibility of recycling efforts to neighbours (Hage et al., 2009). Consistent recycling laws and policies should be implemented by all authority bodies and their enforcement should receive consideration respectively (Jesson et al., 2014). Austria's former environment minister Nikolaus Berlakovich stated several factors as crucial to the success of recycling in Austria: the regulatory framework prescribing the requirements for a sustainable waste treatment, the implementation of economic incentives (producer responsibilities and landfill/incineration tax), regular waste controls and monitoring systems and lastly education and training programmes in combination with comprehensive information campaigns ${ }^{14}$.

In a research based on 46 interviews with waste management experts from Bulgaria and Belgium the "proper legal framework, control, and common and coordinated use of fiscal and ecoinstruments" also turned out to be the top three factors when it comes to the successful implementation of policy instruments (Bozhikin et al., 2017).

\subsection{Positive image of authority}

To raise awareness, public relations and a positive image of the local WM authority play a very important role, particularly when a new separate collection system is implemented (Seyring et al., 2015). As previously mentioned, system trust is an important driving force behind behaviour (3.2.7). Jesson et al., (2014) suggest that "the persuasive influence of local authority messages and communications is enhanced by the existence of a strong and trusted relationship between people and their neighbourhood, and with their local council". To influence behaviour through public policy the MINDSPACE* framework was developed, underlining the importance of the relationship with the delivering messenger and context for effective communication (Dolan et al., 2010). In Hong Kong urbanites perceived the MSWMS as 'broken' or 'non-existent' and the results were low participation and system distrust ${ }^{15}$. The development of a strong leadership in local authorities can be improved through reliability (ability to effectively treat sorted waste), legitimacy (punitive measures) and effectiveness (dissemination of information about the program benefits), such as: strict refuse of unsorted waste by the communal collectors (Loan et al., 2017). Vienna, already enjoying a good image amongst citizens, uses the easy identification of all city collection vehicles through corporate design as a permanent positive advertisement for the authority (Seyring et al., 2015). Noteworthy is the unusual popularity witnessed by Sweden's recycling brand Pantamera by turning Cuban song "Guantanamera" into its official jingle and sponsoring a series of songs using the tune to go with their name - meaning "deposit more"16. They even engaged Swedish musicians to make hit songs about recycling, resulting in ear-worms with lyrics "recycle more"17.

\subsection{Collaboration with community groups}

Another good practice is inviting press and interested stakeholders (associations, NGOs) to explain/demonstrate new steps in the collection system, even better if performed highly-visible or in events (e.g. public sorting of residual waste bin, demonstrating how much recyclables are still in there, etc.), (Seyring et al., 2015). The engagement of local trusted community groups to issue messages can strengthen their impact, help to build neighbourhood pride and improve local area quality (Jesson et al., 2014). A study from Uganda states the involvement of active environmental organizations, women's clubs, church organizations and other associations as necessary (Ekere et al., 2009). For areas with high cultural diversity the involvement of religious, faith and local ethnic community leaders is recommended (GMWDA, n.d.). Ecological mobilization is reinforcing the perception that sorting wastes is what one 'ought' to do (Schwab et al., 2014). "The more people participate in recycling programs by being a member of an ecological association, the more the country's population at large is likely to engage in behaviors such as sorting and separating domestic wastes" (Guerin et al., 2001). The involvement of volunteers to demonstrate and interact on

\footnotetext{
${ }^{*}$ MINDSPACE is an acronym for Messenger, Incentives, Norms, Defaults, Salience, Priming, Affect, Commitments and Ego.
} 
a personal level - the use of an NGO as a 'broker' between residents and the local authority - was found to be a key element for recycling success and habit forming (Xu et al., 2016). The recognition of the informal sector (e.g. waste pickers) and inclusion in the MSWMS is also recommended (Aparcana, 2017; UN-HABITAT, 2010; Wilson, 2015).

\subsection{Communication}

Communication with residents is key to ensuring that they buy into new waste and recycling services and use them effectively ${ }^{18}$. Persuasive Communication has been found to produce attitude/behaviour change and was already used during the 1980 s to encourage recycling and 'manipulate' public commitment (Burn et al., 1986). The framing of messages in terms of content and emotional tone significantly influence how they are received ( $\mathrm{Zhu}, 2016)$. The use of humour is also recommended (Dri et al., 2018). A communication strategy is more likely to work if it addresses a specific audience, is worded in a language familiar to that audience, addresses a specific problem commonly experienced by that audience, presents a solution to that problem and is directed to specific communities (WHO, 2017). Promotional recycling messages need to be customized and targeted in order to better link the different barriers faced by different segments of the population and maximize their impact. Content and message channels should both be highly contextually specific to the infrastructure and system situation (Jesson et al., 2014) as well as culturally sensitive ${ }^{19}$. Communication is suggested to improve the acceptability of WM in the community. Increased acceptance leads to higher participation levels in communal waste activities which in turn improves communication as people have the same level of understanding (Djerf, 1999).

Communication strategy approaches can be based on mass information (e.g. Television, radio, magazines and newspapers) or direct information (e.g. direct mailings, informative sessions, neighbourhood billboards, distribution of calendars with collection schedule) (Vicente and Reis, 2008). The success of an informational intervention depends on the interplay among content, media, and format. Information needs to be permanently disseminated in order to help sustain a newly learned behaviour (Iyer and Kashyap, 2007). Additionally, it is underlined that patience is required until the waste collection system "takes root in society" (Seyring et al., 2015).

\subsubsection{Media}

Apart from careful framing, the right selection of communication media to address recycling is crucial to the success of any campaign (Zhu, 2016). Depending on the targeted audience, the use of flyers, leaflets, social network sites, TV advertisements, posters, brochures, door-hangers etc. may vary in effectiveness. Bigbelly, a platform for smart cities with a focus on waste and recycling solutions, suggests the use of social media or a website dashboard to promote recycling programs and increase participation, share information with the residents about acceptable recyclates and provide contact information ${ }^{20}$. Ljubljana's waste manager Snaga, well aware that qualitative services and communication are the foundation for user satisfaction, maintains three websites and employs the use of social media (Seyring et al., 2015).

Many cities such as Milan ${ }^{21}$ released mobile applications that explain what goes where. Innovation, utilising the latest technology and social media marketing techniques as well as interactive software (e.g. app 'Getting Wasted' playfully testing recycling knowledge in Manchester) is believed to encourage recycling in a "new and refreshing way' ${ }^{22}$. Evidently a mixed use of media channels, capturing all levels of society and tailored to its recipients, is favoured (Bond and Rajaratnam, 2012). It is concluded that a continuous use of media, adjusting to progress and audience, favours the successful establishment of a 'recycling culture'.

\subsubsection{Targeting the household as a collective unit}

Separating waste in the household environment requires integrating the behaviour into the everyday life of all its residents. Thus, the overall recycling performance relies on collective household behaviour. Communications and messages should reflect that all household members must share the 
work as a 'behavioural unit' and not be reliant on one householder (Jesson et al., 2014). The integration of recycling in routines can add to the 'domestic burden' - cooperation, negotiation and conflict amongst the household members involved (Pettifor, 2012). While influencing the individual roles the household division of labour, household organisation should be educated and assisted. Jesson et al., (2014) suggest to identify the householder responsible for recycling activities and 'functionalize' them as an informant for the other people living with them. In this context Iyer and Kashyap (2007) highlight the role of gender and strongly recommend the involvement of women in the promotion of recycling schemes and the use of women-appropriate media in order to maximize the effect of any message. On the other hand it is possible that women cannot 'tell' men to sort their wastes in some cultures (Becker, 2014). Ekere et al. (2009) state that campaigns should address both men and women due to the "complementary nature of their roles".

Further, authorities are criticized for not distinguishing between the terms "households" and "properties"; the former should be recognized as dynamic units "due to the nature of people living their lives'. Messages aimed at motivating recycling should change over the time of residence, concurrent with the changing reasons for households to not recycle (Timlett and Williams, 2009) . To advance influencing behaviour change, continued research is necessary to understand collective recycling behaviour and the division of domestic routines amongst household members (Jesson et al., 2014; Miafodzyeva and Brandt, 2013).

\subsubsection{Reaching out to new residents}

The distribution of welcome (or information) packs that detail the community's recycling programs is recommended to engage with new homeowners - encouraging participation and recycling behaviour from day one in their new community ${ }^{23}$. Explaining the system to them as an 'induction' is suggested (Jesson et al., 2014), possibly in combination with a 'pledge' (Bond and Rajaratnam, 2012).

\subsubsection{Language}

Residents from different cultures often have difficulty relating to recycling information and understanding it and require simple and consistent messages developed within the community (GMWDA, n.d.; Timlett and Williams, 2009). Experience of 'nudge' experiments suggests the use of plain language ${ }^{24}$. Additionally, non-native residents need to be acknowledged (Timlett and Williams, 2009). In order to deal with language difficulties and to make messages graspable for areas with a high ethnic diversity, the distribution of information in several languages (Bernstad, 2014) is recommended along with working with locally recruited ambassadors (5.3) and culturally appropriate media ${ }^{25}$. Bernstad also mentions the uniform use of colours and symbols. A study by Miafodzyeva (2012) pinpoints the "provision of clear, understandable and easily accessible written information in ethnic languages, supported by "word-of-mouth" [emphasis added] information". To improve the lack of information amongst San Francisco's residents whose first language is not English, the Department of the Environment reaches out by sending staff into multicultural neighbourhoods to talk directly with residents, often using pictograms and multilingual signage about how to recycle correctly ${ }^{26}$.

\subsubsection{Door-Stepping}

The Greater Manchester Waste Disposal Authority recommends face to face engagement as the most effective form of communication to change behaviour (GMWDA, n.d.). A common technique to deliver recycling messages is "door-stepping", "a form of direct marketing that involves faceto-face conversations with residents on their doorstep about their waste and recycling services" 27 , based on the idea that a conversation with an individual can impact household behaviour (Jesson et al., 2014). In the UK, the NGO "Keep Britain Tidy" successfully delivered more than 100 doorstepping campaigns, 'knocking on over 1.5 million doors and engaging with more than half a million residents ${ }^{28}$. On suggestion of the Ecological Recycling Society (NGO) a door-to-door infor- 
mation campaign was also implemented in Elefsina (Greece). Whilst providing all the available information regarding recycling facilities, the citizens' opinion regarding the performance of the MWMS was also recorded (R4R, 2014a). Another suggestion in favour of easy, low-cost methods is to engage with residents at the point of service delivery, possibly through the collection crew (Timlett and Williams, 2008).

\subsubsection{Message frequency, reminder}

Another important consideration is message frequency - frequent interventions are needed as a reminder for consumers about recycling and its importance for resource conservation (Iyer and Kashyap, 2007). In Ljubljana (Slovenia) residents can set up a free SMS-reminder of the waste collection schedule, monitor collection costs and update their services (Oblad, 2018). In Austin (Texas) the 'My Schedule' tool is used, making it possible for users to easily add their personalized collection schedule to their Google or Outlook calendar ${ }^{29}$.

Furthermore, reliable and regular collections help to embed a habitual recycling 'rhythm' (Jesson et al., 2014). In Taiwan, the trash trucks play classical music so people know when to leave the house and dispose of their wastes. Taipei lets users use mobile apps to track the trucks and alert them whenever a garbage truck is nearby ${ }^{30}$.

\subsection{Public education}

As previously stated (3.2.2), lack of public knowledge is widely accepted as one of the most important (information) barriers to the success of any MSWMS (Ma and Hipel, 2016). The best practice to overcome the predominant recycling barriers (knowledge, attitudes, perceptions) is by campaigning to raise awareness (Dri et al., 2018).

\subsubsection{Education and information programmes}

Educational and informative programmes are essential to successfully enhance recycling (Miafodzyeva and Brandt, 2013; Timlett and Williams, 2009). It is expected that "providing residents with information on what is recycling (declarative knowledge) and how to recycle (procedural knowledge) will modify their attitude toward recycling and future recycling behaviours" (Iyer and Kashyap, 2007). San Francisco states 'education' as the most important element for success ${ }^{31}$. In Vienna, which received the "World City Closest to Sustainable Waste Management" award in 2010, awareness raising/communication also played a key role (Seyring et al., 2015). Public education in turn is impacted by socio-economic factors, e.g. individual preferences regarding communication channels (TV, newspaper, internet) (Ma and Hipel, 2016). Thus, it is advisable to accompany each step of change or MSWMS adjustment with targeted awareness campaigns to motivate users to utilise the different information channels (Jesson et al., 2014; Seyring et al., 2015). In Ljubljana, intensive communication campaigns before and during the introduction of the new MSWMS are mentioned as leaders to success; impressively, the city raised its recycling rate to $61 \%$ within 10 years (and recovered materials increased from $16 \mathrm{~kg}$ in 2004 to $145 \mathrm{~kg}$ per person in 2014) (Oblad, 2018). The well designed and managed communication strategy was conducted in cooperation with relevant stakeholders including the media, local NGOs and the European Parliament Information Office and gained public support and engagement, which achieved great results and even won an award in content marketing (Oblad, 2018; Seyring et al., 2015).

For information-based instruments to have any chance of success the Global Waste Management Outlook suggests that the waste-related information has to be relevant to people's daily realities and concerns (Wilson, 2015). In order to shape attitudes, an emphasis on feelings (good, rewarding) or consequences (saving resources, reducing pollution etc.) is proposed (Wan et al., 2017). The households need clear "how-information" - that a recycling scheme exists and knowledge about what, where, when and how to recycle (Iyer and Kashyap, 2007; Varotto and Spagnolli, 2017). To help eliminate confusion the use of uniform educational materials across communities is suggested - even if those communities accept different materials as recyclable ${ }^{32}$. It should be made very 
clear what can and cannot be placed in each bin while it is suggested to cultivate interest about how waste is managed in the general population (Seyring et al., 2015).

One of the biggest barriers to food waste recycling detected in the UK, was the residents' attitude of "why bother?". It highlighted the need of communicating reasons why it makes sense to recycle food waste as well as how the technology brings about the benefit in practice (e.g. food waste to energy). The related recommendation for communication concerns advice and reassurance of the people about safe and hygienic in-house food waste containment to overcome attitudinal barriers (Jesson et al., 2014).

\subsubsection{Waste awareness and education for children}

One approach for new educational programs is the focus on children education and schools; laying the grounds at an early age is supposed to encourage recycling behaviour regardless of location $^{33}$. In turn, it is suggested that children can act as ambassadors on recycling issues in their homes, educating and pushing their parents to behave in the way they are taught to behave (Becker, 2014; Varotto and Spagnolli, 2017). In Tallinn (Estonia) a great demand for environmental awareness programs and campaigns led to an expansion of the number of hours dedicated to environmental issues in school and kindergarten curriculums (R4R, 2014b). In Canberra (Australia) a sustainable schools initiative (AuSSIACT) along with facilitating learning opportunities at household recycling facilities and landfills are regarded as key education initiatives and included in the WM strategy (ACT, 2011; Pickin and Randell, 2017). In Portugal, children have also been identified as important targets of communication campaigns and are involved in recycling messages on TV and radio (Vicente and Reis, 2008). The awareness campaign "Prügihunt" ("Waste Wolf") 34, which started 2003 in Tallinn and spread nationwide enjoyed great success. It aimed to draw attention to the necessity and possibilities of sorting waste amongst all demographic groups, especially targeting kindergarten, primary and secondary school students and educational staff. Different communication tools and pedagogical materials are planned annually respecting the demands of target groups and 'lessons learned' (e.g. provision of educational play cards, exercise books). What has been provided in schools and kindergartens, outdoor public events and a "Waste Information Trailer", disseminated through TV clips and the internet (Facebook) and with the well recognizable mascot "Waste Wolf" has gained popularity amongst children ${ }^{35}$ and won several national awards as the best environmental campaign. Factors identified for success are benchmarking methods and expert judgement (R4R, 2014b).

\subsection{Social modelling}

A meta-analysis revealed social modelling and environmental alterations as the most effective basis of persuasive strategies to promote household recycling. The basic idea of social modelling is 'learning to imitate others', based on Bandura's social learning theory (Varotto and Spagnolli, 2017).

\subsubsection{Presentation of social norms}

As described in section 3.2.3, social influence and social pressure can be used as a stimulus to encourage more waste reuse and separation (Ekere et al., 2009). It is suggested to promote recycling behaviour as a desirable social trend (Wan et al., 2017). Messages should provide information of injunctive (i.e., social acceptable behaviours) and descriptive (i.e., behaviours displayed by others) norms (Wan et al., 2017). According to social-psychologist Robert Cialdini, presenting social norms related to recycling is a powerful influence technique to affect recycling action ${ }^{36}$. People would have such a strong conformity desire that they are more likely to change their ways if they think their neighbours are doing the same. He emphasizes that the effectiveness of a message can be improved significantly by simply framing it differently ${ }^{37}$. Replacing standard ecological messages with social norms increased recycling in Arizona: In TV adverts people who were already recycling spoke favourably of it while derogating another (non-recycling) person. In another experiment, 
Cialdini persuaded hotel guests to reuse their towels with a notice saying that most people who previously stayed in that room had reused them (rate rose by $26 \%)^{38}$. Applied to waste sorting, this may also work in the context of new home owners.

\subsubsection{Social punishment}

Another way of enforcing 'good' behaviour is using shame: a common strategy for jurisdictions is using stickers: visible to neighbours and thereby causing social pressure. For instance, in Seattle residents who failed to comply with the regulations found their bins marked with a bright red stick$\mathrm{er}^{39}$. In Chicago, haulers marked carts with an "oops tag" if they found items that can't be recycled $^{40}$. As practices designed to embarrass citizens can become quite unpopular ('scarlet letter'41), an approach that is simple, cheap and uses social norms in a non-punishing manner is preferable. A successful initiative in Nova Scotia (Canada) encouraged households who already recycled to mark their bins with a statement and talk to their friends and neighbours about composting in order to remove common concerns and persuade non-composters (Southerton et al., 2011). The 'Golden Ticket' initiative in Manchester was very successful: recycling bins that were sorted correctly were tagged. The tags could then be redeemed into rewards for local primary schools, which motivated the whole neighbourhood. This community-based recycling rewards scheme was part of the Up and Forward project, carrying out 42 innovative campaigns to demonstrate that improved communication can enhance waste prevention and recycling in 'hard to reach' communities ${ }^{42}$. For rewards see 5.8.3.

\subsubsection{Comparative Feedback}

Providing individuals or groups with information regarding their recycling behaviour along with a comparison to a predefined standard (feedback interventions) can motivate households to "fill the gap' and fulfil this standard (Varotto and Spagnolli, 2017). Displaying socially comparative feedback was shown to significantly increase recycling behaviour and decrease sorting errors (Dupré and Meineri, 2016). Historical comparison with one self's past behaviour can be equally 'fruitful' (Varotto and Spagnolli, 2017). It is recommended to communicate the metrics of success (monthly and yearly recycling rates, diversion from landfills, etc.), to explain the benefits of recycling and share details about the recycling supply chain via community newspapers, a newsletter containing feedback or posts in social networks ${ }^{43}$. Computer-based feedback systems can automatically track recycling activity and send current and tailored feedback on personal mobile devices or ambient displays (Varotto and Spagnolli, 2017). It appears that feedback is most effective when repeated from time to time (Nomura et al., 2011).

\subsubsection{Neighbourhood block leaders}

Another approach based on micro-level communication is the recruitment of community members as 'block leaders' for model recycling behaviour and to inform and convince non-recycling neighbours. This is suggested as being more effective than solely providing information (Varotto and Spagnolli, 2017). As an illustration: Xu et al. (2016) recruited volunteer advisers to stand beside the waste stations every morning and evening and support resident recycling by physical demonstration and explanation 'in a positive and friendly way'. Becker (2014) suggests employing recycling ambassadors within strong social groups (families, immigrant clusters, students in housing); they would have a broad range of influence. She also mentions retired people as an appropriate group to work with. Other names used for such advisers are "Eco Patrol", "Recycling Ambassadors" and "Zero Waste Agents". Block leaders may support door-stepping campaigns (Dai et al., 2015). In Manchester, an ambassador campaign was used to especially target 'hard to reach' apartment blocks (GMWDA, n.d.). Particularly for areas with little visibility, working with agencies such as housing associations and home care support is recommended to help people adapt a routine behavioural pattern (Jesson et al., 2014). 


\subsection{Environmental Alterations}

Citing 'psychology of recycling' expert Jessica Nolan: "Obviously if the infrastructure is not there, you can't expect people to participate in a program that doesn't exist" ${ }^{44}$. Environmental alterations are interventions making recycling easier and more convenient by modifying the physical environment, e.g. adding bins in proximity, changing their appearance or provision of home sorting equipment (Varotto and Spagnolli, 2017). As best practice in Vienna, making the container location easily accessible while keeping them new, clean and well labelled was advocated (Seyring et al., 2015). Furthermore, addressing typical practical concerns (such as unpleasant odours or bag breaking) with improved bin design can increase the proportion of sorting households. As shown in Catalonia, a higher satisfaction of source-separation can be achieved by bringing aerated bins for the storage of organic household wastes into use (Puyuelo et al., 2013).

\subsubsection{Collection scheme}

Door-to-door collection systems are a recognized best practice to improve recycling behaviour and result in the highest capture rates of recyclables (R4R, 2014a; Seyring et al., 2015).

The introduction of door-to-door collection was key factor for Ljubljana's sharp increase in recycling rates, especially ascribed to separately collecting biodegradable wastes (Seyring et al., 2015). In Chennai (India) door-to-door collection and source segregation were successfully promoted by cooperating with the local authorities and WM staff. Households are required to separate all recyclable materials and can then give them away to waste pickers (Kurian, 2006).

In contrast some householders prefer 'bring sites' ('micro recycling centres'), mainly due to absence of space for large containers in kitchens, backyards etc. Practical recommendations include long opening hours and provision of small containers for pre-separation (Williams and Taylor, 2004). A convenient location for such 'bring banks' are supermarkets, eliminating special trips for recycling (Jesson et al., 2014). Strategically located collection points, accessible to both the recycling company and within walking distance to residential units, are also recommended for typical townhouses in Equestria (South Africa), where curbside collection is difficult. Design and location should support the maximisation of accessibility and visibility to non-recyclers in order to establish a communal recycling practice (du Toit et al., 2017).

\subsubsection{Provision of bins}

In the UK, recycling rates increased significantly when the appropriate waste infrastructure was installed through the provision of recycling bins/boxes and curb-side collection facilities (Southerton et al., 2011). Similar success was reported in Toronto, where building managers received free resources for distribution to residents that fit under the kitchen sink (Bond and Rajaratnam, 2012).

The installation of hangers for food waste collection in each household kitchen in a Swedish residential area not only improved the convenience for separation but also gave residents the strong indication that everybody in the area should separate - the social norm of separating food wastes was enforced by the property owner (Bernstad, 2014). Such interventions in material infrastructure can create the conditions for new habits to emerge and have the potential to 'lock people into sustained environmentally friendly behaviours' (Southerton et al., 2011).

\subsubsection{Recycling-bin-to-garbage-bin ratio}

Another practice in order to encourage recycling behaviour is reducing the size of refuse bins in comparison to the recycling bins. The smaller bin-size acts as a visual sign when something is discarded. In Edinburgh the introduction of smaller refuse bins 'boosted recycling rates by $85 \%{ }^{\prime 4}$. Zero Waste Scotland suggests this as a 'nudge marketing' approach: the size difference would 
provide a degree of 'choice editing' where recycling looks more important and also accessible ${ }^{46}$. In many cities residents can decide which size of garbage bin fits their needs best. Combined with Pay-As-You-Throw (PAYT) schemes (5.8.1), this is a "the smaller the bin, the less you pay" initiative.

\subsubsection{Design and Labelling}

Ultimately, the visual (smart) design of collection points is crucial to positively influence convenience (Dolan et al., 2010; Miafodzyeva and Brandt, 2013). Simple changes such as colour and the shape of the hole - specialized recycling container lids - can dramatically increase recycling behaviours (Duffy and Verges, 2009). Vienna suggests a professional (corporate) design for easy identification and recognition (Seyring et al., 2015). To make it easier for the recycler, it is recommended to have one single image (sticker, etc.) for a given material that is then used everywhere ${ }^{47}$. The labelling of 'landfill' instead of 'trash' or 'waste' is used as a 'nudge' reminder to keep recyclables out of the garbage ${ }^{48,49}$. Labels designed with yes/no instructions including images of both the items that can be thrown into the bin and which cannot have also proven success ${ }^{50,51}$. Indeed, this seems to be the best practice to ensure correct separation and handling the confusing problem of different MSWMS accepting and refusing different materials. Optimally, the recycling-information is provided on the products themselves (Dri et al., 2018). The 'Green Dot' label for packaging, originally from Germany and now active in 28 countries, informs the consumers directly about the producer's involvement in an official recovery scheme (Wilson, 2015) and is seen as one of the key success factors for building the 'recycling culture' among the public in Germany ${ }^{52}$. The legal implementation of 'extended producer responsibility' strongly supports this (Becker, 2014; EC, 2015; Zaman and Lehmann, 2011).

\subsection{Economic incentives}

The effort taken to conduct recycling activities is voluntary in most municipalities and without the implementation of economic incentives, provides little reward. Aligned with the utility-maximisation approach (3.3), recycling behaviour can be regulated by an "adequate manipulation of rewards and punishments [emphasis added]" (Miafodzyeva, 2012). Serving as external motivators, monetary incentives can be positive and negative (disincentive, e.g. tax), (lyer and Kashyap, 2007). Financial rewards are very popular among the public, while penalties seem less politically acceptable (Defra, 2007; Li et al., 2017; Widdowson et al., 2014; Yau, 2012). On the other hand, economic incentives are expected to result in less persistent changes than those coming from informationbased intervention programs (lyer and Kashyap, 2007).

\subsubsection{Fee system: Pay-As-You-Throw}

One strategy is the implementation of fee systems where the costs for WM are allocated according to amount of waste generated (Reichenbach, 2008). While curb-side programs reduce the household's perceived cost of recycling (commonly financed via general tax/flat fees), unit pricing poses a price on the disposal of different waste streams (i.e. higher fees for not recycling), (Jenkins et al., 2003). Commonly termed "Pay-as-you-throw"(PAYT), this financial incentive increases recycling activity coupled with efforts to minimise overall waste production (Reichenbach, 2008). On average, cities applying PAYT have better collection rates than others (Seyring et al., 2015). In San Jose (California), a 'nationally recognized leader in waste management', the first year of PAYT produced an increase of recyclables by $149 \%{ }^{53}$. The payment scheme can be volume-or weight-based; the local authorities should examine which solution matches best with the local conditions. Finding 
a good and fair combination of fixed and variable fee components and ensuring accountability is crucial for household acceptance and long-term success (Reichenbach, 2008). Fee systems that allow households 'to save money' by better sorting are considered to be more encouraging than flat rate or top-up systems. It's suggested to select a relatively high basic fee and subsequently decreasing it depending upon a reduction in collection frequency or residuals (Seyring et al., 2015). Not charging at all or connecting the waste fee to other services is regarded as discouraging participation (Seyring et al., 2015).

San Francisco's waste collector Recology introduced the "Fantastic Three" (waste streams) in 1999 (Bradford et al., 2018) and has since then given vast financial incentives to residents who voluntarily reduce the size of their bins or pick-up-frequency ${ }^{54}$. Within months, the diversion rate for participating businesses and residents increased by more than 90 percent.$^{55}$ Fees for trash are about 10 times higher than those for recycling and compostables ${ }^{56}$. Cities like Ljubljana and Budapest set fees on residual waste (which fund the collection) and provide the service of collection of recyclables without user charges in order to incentivise separation (Seyring et al., 2015). In Vienna, a volume-based fee on residual wastes and emptying frequency in combination with free of charge disposal via door-to-door and 'bring points' collection is successful (Seyring et al., 2015). Contarina (WM company in Veneto, Italy), having reached source separation levels of up to $85 \%$, splits its fee into a fixed (depending on members living in household) and variable part. The latter is calculated with a penalizing variable (times non-recyclables collected) and a bonus variable ( $30 \%$ reduction for home-composting) (Simon, 2018). In Seoul (South Korea), a Radio Frequency Identification System with incorporated personal ID cards is used to charge residents for the amount of food they discard $^{57}$. Although the system is very successful, it is found that the effects of the volume-based waste fee system in Korea are only temporarily and inherit the risk of illegal dumping (Park, 2018; Park and Lah, 2015). This is also a major concern regarding variable charging systems (Ma et al., 2018). Representatives of Vienna suggest to 'keep the fee system simple, traceable and flexible', mentioning that for example one call should be enough to reduce bin volume (Seyring et al., 2015). SUEZ's external affairs director Gev Edulje states: "Paying less for disposing of less, coupled with well-designed service arrangements and a properly funded householder engagement programme, has been universally recognised as a potent, cost-effective package of measures for raising recycling performance. ",58

\subsubsection{Fines}

The reverse strategy is to "punish" recycling-unfriendly behaviour. While cities such as San Francisco $^{59,60}$, Seattle ${ }^{61}$, Vancouver ${ }^{62}$ and Woodbury ${ }^{63}$ effectively penalize residents and building owners for not separating their trash properly with fines, policy violations in some areas of Taiwan can additionally be met with public humiliation. Video cameras have been installed to catch violators and the footage published after the second violation with the offender's face blurred out. Sometimes half of the collected fines are offered to citizens who help the authorities catch those who don't separate their trash ${ }^{64}$.

\subsubsection{Positive Rewards}

Varotto and Spagnolli (2017) refer to incentives as 'any kind of benefit' the resident receives for participating in the recycling program, mentioning monetary rewards, refund and unit pricing programs, gifts, prizes, lottery tickets and discount coupons. It appears that in areas where recycling is an already established practice, the incentives have to be more 'profitable' for the householder (Widdowson et al., 2014; Woodard et al., 2000).

\section{Deposit Refund Systems}


One way to facilitate recycling of certain packages (especially refillable beverage containers) and delivering the purest material fractions (Seyring et al., 2015) as well as achieving high collection rates are mandatory deposit-refund systems. Lessons from Sweden show their effectiveness depends on (1) density of return sites, (2) deposit size and (3) efforts and time put to raise awareness. In order to increase return rate the deposit size was adjusted several times (Miliute and Plepys, 2009).

\section{Vouchers}

A more innovative incentive to boost recycling behaviour - in line with before-mentioned "nudge" theory - is a "recycling bank" program. Recyclebank ${ }^{65}$ is an educational platform, rewarding residents for their recycling efforts with vouchers which they can exchange at local businesses or online $^{66}$. It proved to be successful when tested in large cities such as London and Philadelphia (GAO, 2006; Widdowson et al., 2014). A similar approach to help residents separate their waste is followed by De Gezonde Stad (Healthy City) in Amsterdam by opening an accessible and welcoming 'Zero Waste Lab'. Fostering a strong neighbourhood community, residents can hand in their separated waste and get value coins in return which they can spend in local shops of cooperating entrepreneurs in the same area ${ }^{67}$ Another original and very successful initiative to recover recyclable materials was launched in Mexico City: the Mercado de Trueque (Barter Market) pops up every month across the capital and residents can exchange recyclables for "puntos verdes" (green points), which then can be used at the nearby farmers markets (simultaneously incentivising people to buy fresh local food) ${ }^{68}$. In a study conducted by Li, Huang and Harder (2017) in Nanjing, household separation results were displayed on large posters near the bins and the number of 'green points' each apartment received. Best households were denoted with red text. Residents could exchange their points for eggs, dish washing detergent and other services (e.g. sharpening knives). It was observed that residents really cared about the number of eggs they got and "talked numbers" with each other, resulting in non-sorters interest in eggs.

While some psychologists suggest that rewards needn't be personal and information about benefits of recycling for the community would be enough ${ }^{69}$, others state that individual-based incentives are more effective than those rewarding a group-performance (Varotto and Spagnolli, 2017).

It appears that the most successful reward incentives involve schools and community groups (Defra, 2007).

\section{Good practices for compact cities}

According to George Monbiot sustainable cities must be compact and high-density and need strict urban planning in order to not collapse ${ }^{70}$. Clearly, effective WM and resource recovery are crucial ${ }^{71}$. A variety of definitions for 'compact city' are in use, but the concept of urban planning generally refers to cities with contiguous development patterns, high density areas of housing and population with mass-transit linkages and accessibility to diverse local services and jobs (Matsumoto, 2012).

\subsection{The problematic of household recycling in compact cities}

While high population density is regarded as a key factor for the 'viability' of recycling programs and curb-side collection (Saphores et al., 2006), policies to concentrate population appear to conflict with the aim to increase recycling rates in urban areas (Timlett and Williams, 2009).

Urban households - especially flats (Timlett and Williams, 2008) - are found to separate less than those in more rural areas (Ekere et al., 2009; Miafodzyeva and Brandt, 2013). With increasing population density recycling decreases (Hage et al., 2009). Several of the afore-mentioned social factors become intrinsically significant in high-density urban areas. As housing density increases, it is anticipated that issues of reduced convenience, less visibility and normalised behaviour become more notable with higher population flux, less affluent population etc. (Timlett and Williams, 2009).

"Transience, high social mobility, social dis-engagement with 'place' and busy lifestyles are common features of both flat dwellers and young people and these factors combining with the un- 
promising physical infrastructure of flats conspire to bring together a raft of barriers in one setting" (Jesson et al., 2014). The interrelation between building type, form of tenancy and associated lifestyles and situations combined with infrastructural, systemic and knowledge barriers make the encouragement and organisation of separate collection in multi-store houses especially challenging (Jesson et al., 2014; Seyring et al., 2015). One major reason for low collection rates in compact cities is the growing scarcity of appropriate space for temporary storage (Jenkins et al., 2003; Timlett and Williams, 2009). Another significant issue in urban areas is greater population transience. Global population mobility and migration create "highly diverse, multi-cultural environments" (Jesson et al., 2014). Therefore, Miafodzyeva (2012) highlights the necessity of understanding the recycling participation of different ethnic groups and the support of multicultural householders which make up a large part of the population in major cities. Moreover, people are intrinsically mobile and live only temporarily in different places, often having established a recycling routine in their country of origin and are likely to be familiar with the local MSWMS (Jesson et al., 2014).

\subsection{Considerations for high-density areas}

Considerations for improving waste separation in high-density areas are suggested to include social, architectural, technological, infrastructural and organisational factors (Timlett and Williams, 2009).

\subsubsection{Working with property owners, architects and private waste managers}

In order to deliver well focused and scheduled communication campaigns to residents, it is suggested to work with information from council tax or local estate agents (Timlett and Williams, 2009). The High Rise Recycling Project (2014), Melbourne, recommends promoting available programs to owners corporations, facility and building managers and directly to apartment owners. Training them can ensure the correct passing-down of recycling knowledge ${ }^{72}$. In general, convenient WM practices and infrastructure should be implemented from the beginning, addressing outlined problems at the design stage with realistic and innovative sustainable solutions (Timlett and Williams, 2009). It is proposed to publish clear urban planning and design guidelines regarding the involvement of recycling facilities in new-build properties within the legal framework of WM (du Toit et al., 2017; Timlett and Williams, 2009). This necessarily involves the attention of planners and architects who are involved in the (re-)design of settlements and housing complexes. To assure proper access to recycling services for all residents, it is already common practice to make it mandatory for building holders.

In San Francisco, owners are fined if they fail to provide their tenants with the adequate bins and information on how to use them ${ }^{73}$. In Chicago, a city ordinance mandates property owners of multitenant or high-density buildings to contract private companies for the provision of source-separated recycling services and educate their tenants (if not complied, penalized) ${ }^{74}$. Employing a complicated network of private waste managers with many different education approaches and recycling rules results in the city suffering from uneven implementation ${ }^{75}$. Vienna 'learned its lesson' and recommends keeping the waste collection system completely in municipal ownership: it would be much easier to appropriately respond to criticism, develop a successful overall communication strategy (e.g. corporate bin design) and avoid loss of public image (caused by other companies) (Seyring et al., 2015). On the contrary, privatisation changed the system towards a stronger focus on service and communication in Dublin. The WM companies take special care to obtain clear waste fractions (economic interest), while engaging a collection company forces the households to take interest in how their waste is managed (Seyring et al., 2015).

\subsubsection{Dealing with small storage space}

While general suggestions include the broad promotion of how recycling works in apartment buildings (City of Melbourne, 2014), it is highlighted that "those living in high density housing need to know what they can do to maximise the limited space that is available for them to recycle" 
(GMWDA, n.d.). Further, it's recommended to address issues associated with infrastructure and convenience, which are most probably the barriers to participate in recycling (Timlett and Williams, 2009). Solutions to deal with minimal storage space in the home or in external areas "must be tailored to existing exigencies of the built environment" and "need to include broader infrastructural factors such as functioning lifts and convenient, safe storage facilities" (Timlett and Williams, 2009). As the uncontrolled use of bins can become problematic in high-density areas, bin security should also be taken into account (Bond and Rajaratnam, 2012).

\subsubsection{Tailor solutions to type of building}

It was shown that barriers to separation at source are very context-specific. Therefore the provided recycling service and communication campaigns should be designed on a situation-specific basis, tailored to different types of property whilst taking the social circumstances and lifestyles of people living in them into account (Jesson et al., 2014; Timlett and Williams, 2011, 2009, 2008).

Regarding the diversity of 'flats' in urban areas and associated specific barriers, a typology of 12 distinct types was developed in order to tailor the WM service to each category (Jesson et al., 2014). Additionally, it's suggested to "develop a standard suite of educational and infrastructure items, where the selection of items can be tailored for each building" (City of Melbourne, 2014).

As an example for the work with given situations: Typical buildings in Milan have courtyards for the storage of bins and concierge services and new buildings are required to allocate specific place for bins. While operative staff fines contamination, "the main checking mechanism is really the social control that is exercised by neighbours within the block and the concierge inspecting the bins before setting out the bins" 76 .

In Sweden, convenience may be increased by the situation of an recycling room in the basement of an apartment building or in the yard behind several buildings (Miafodzyeva, 2012). In Singapore's high-rise buildings, rubbish chutes are installed, which require other approaches such as implementing a pay-per-opening system for common central refuse chutes, using radio frequency identification tags ${ }^{77}$. San Francisco overcame the 'chute-challenge' of multi-unit buildings by requiring new buildings to install three chutes (or diverter system) and old single-chute-buildings to place recycling containers next to each chute or block them off and provide the three required recycling bins somewhere else ${ }^{78}$. The Hong Kong Government made the provision of refuse storage and material recovery rooms on every domestic floor compulsory, which is considered to be an example for ineffective policy caused by unrealistic assumptions and lack of inclusive public consultation (Yau, 2012). The study reaffirmed the need for environmental education and financial incentives. A study of recycling in high density dwellings by Bond and Rajaratnam (2012) reviews the advantages and issues of door-to-door, bring sites, chute and floor-by-floor systems in detail, for which is no space here.

Once again, the essentiality of a mixed-methods approach to promote domestic waste separation was demonstrated, in high-rise cities just as in all other contexts. There is no 'one-size-fits-all' solution - every building has different managers, measures of storage space and diverse residents with varying motivations. Apart from the need for public education the property owners, tenants and waste managers have to work together and come up with a plan for each building.

\section{Conclusions and Outlook}

The purpose of this literature review is to support WM practitioners and policy makers from different backgrounds in the understanding and motivation of household waste separation behaviour. The research emphasizes the relevance and consideration of its underlying social factors when it comes to the successful implementation of MSWMS. Targeted communication and educational programmes that involve the community and present sorting wastes as a social norm are crucial for the establishment of a 'recycling culture'. Accompanied by environmental alterations and economic incentives, the effort taken by households should be acknowledged and recycling made as convenient as possible. As social factors are influenced to a large extent by the given external conditions, 
tailoring the system to the given local infrastructure arises as a very important remark, especially for high-density areas and buildings. The compilation of interdependent influences on the recycling performance of urban areas highlights the need for sound planning and carefully designed behaviour change strategies. It is demonstrated that social behaviour and barriers to recycling can differ tremendously between urban areas. They have to be investigated in depth before the implementation of new interventions and systems - then tested and monitored. Clearly there is not one applicable solution that guarantees successful behaviour change. A synthesis of demographic, situational, psychological, financial and legal approaches has to be brought in balance to suit the local context. Systems that are sensitive to cultural peculiarities and adjust to the needs of its users over time are more effective in encouraging and maintaining household recycling behaviour in the long term. Along with this, further research is necessary.

The review revealed several shortcomings and gaps, which can serve as inspiration for future research. First, the published literature on social factors influencing household separation behaviour from South America and Africa is highly underrepresented to non-existent. Future studies could identify the most influential social factors and the most effective policy instruments for successful recycling schemes in high-density African and South American cities (e.g. Cairo, Mexico City) and ideally compare them with Western/European results. Following the urbanization trend, these results could be of tremendous importance. Multi-lingual collaboration with native researchers and institutions could deliver these. Secondly, more studies are needed on collective household behaviour (5.4.2) and the motivation of recycling in rapidly changing urban areas that lack the visibility of sorting or have a low sense of community (6.1). Thirdly, it would be valuable to identify the factors that influence the growing number of people that is practicing a mobile lifestyle (e.g. short-term residents, long-time-travellers) and which are confronted with ever-changing recycling systems in different countries, cities and buildings. This issue, mentioned in section 3.2.2, could be addressed with a comparative study of recycling systems from the household recycler's perspective (incl. colour schemes, accepted materials) and deliver useful results in order to reduce barriers to recycling and develop a less complex, standardized system. Finally, with regard to the current demographic trends, future studies should focus in particular on waste separation behaviour and the adaptation of the technical environment in skyscrapers and apartment buildings in different urban areas.

The present results are relevant in the field of sustainability research and contribute to the understanding of the international and transdisciplinary challenge of household waste separation behaviour. The information provided ensures that newcomers to the subject as well as specialists receive new and in-depth insights. The work presents many approaches for the development of practicable solutions, but is supposed to serve solely as a basis for context-specific investigations. Equally to the waste challenges faced, the presented variety of recommendations from and for cities across the globe highlights the potential of collaboration and learning from one another's experiences and practical insights. A dialogue on best practices among practitioners worldwide is necessary of which everybody can benefit. 
This is an Accepted Manuscript of the article Knickmeyer, Doris. "Social factors influencing household waste separation: A literature review on good practices to improve the recycling performance of urban areas." Journal of Cleaner Production (2019): 118605, available online at https://doi.org/10.1016/j.jclepro.2019.118605 @2019. This manuscript version is made available under the CC-BY-NC-ND 4.0 license.

\section{Acknowledgements}

The advice of Adriana Artola Casacuberta during the research and writing of this paper is gratefully acknowledged. I would also like to thank Peter Taylor for proof reading the article and my anonymous reviewers for their valuable comments and suggestions.

This research did not receive any specific grant from funding agencies in the public, commercial, or not-for-profit sectors.

\section{REFERENCES}

ACT, 2011. ACT Waste Management Strategy, Towards a sustainable Canberra. Australian Capital Territory (ACT) Government, Environment and Sustainable Development.

Ajzen, I., 1991. The theory of planned behavior. Orgnizational Behav. Hum. Decis. Process. 50, 179-211. https://doi.org/10.1016/0749-5978(91)90020-T

Ando, A.W., Gosselin, A.Y., 2005. RECYCLING IN MULTIFAMILY DWELLINGS: DOES CONVENIENCE MATTER? Econ. Inq. 43, 426-438. https://doi.org/10.1093/ei/cbi029

Aparcana, S., 2017. Approaches to formalization of the informal waste sector into municipal solid waste management systems in low- and middle-income countries: Review of barriers and success factors. Waste Manag. 61, 593607. https://doi.org/10.1016/j.wasman.2016.12.028

Bandura, A., 1971. Social learning theory. Soc. Learn. Theory. https://doi.org/10.1111/j.1460-2466.1978.tb01621.x

Barr, S., 2007. Factors Influencing Environmental Attitudes and Behaviors. Environ. Behav. 39, 435-473. https://doi.org/10.1177/0013916505283421

Barr, S., Gilg, A.W., Ford, N.J., 2001. Differences Between Household Waste Reduction, Reuse and Recycling Behaviour : a Study of Reported Behaviours , Intentions and Explanatory Variables. Environ. Waste Manag. 4, 69-82.

Becker, N., 2014. Increasing High Recycling Rates, Socio-demographics as an additional layer of information to improve waste management. Lunds universitet Internationella miljöinstitutet (IIIEE).

Berglund, C., 2006. The assessment of households' recycling costs: The role of personal motives. Ecol. Econ. 56, 560569. https://doi.org/10.1016/j.ecolecon.2005.03.005

Bernstad, A., 2014. Household food waste separation behavior and the importance of convenience. Waste Manag. 34, 1317-1323. https://doi.org/10.1016/j.wasman.2014.03.013

Bernstad, A., la Cour Jansen, J., Aspegren, A., 2013. Door-stepping as a strategy for improved food waste recycling behaviour-Evaluation of a full-scale experiment. Resour. Conserv. Recycl. 73, 94-103. https://doi.org/10.1016/j.resconrec.2012.12.012

Bond, V., Rajaratnam, T., 2012. Assessment of Options for the Provision of Waste Infrastructure and Procurement Services - Recycling in High Density Residential Buildings. Hyder Consulting, Sydney.

Bozhikin, I., Gechev, R., Dentchev, N.A., 2017. Environmental fiscal policy and other instruments for sustainable and efficient municipal solid waste management: a comparative study of Belgium and Bulgaria. Waste Manag. 65, IIII. https://doi.org/10.1016/S0956-053X(17)30390-2

Bradford, A., Broude, S., Truelove, A., 2018. Trash in America. Moving from Destructive Consumption to a ZeroWaste System. TexPIRG.

Brook Lyndhurst, 2007. Establishing the behaviour change evidence base to inform community- based waste prevention and recycling Technical. Brook Lyndhurst.

Burn, S., Psychology, S.O.-J. of A.S., 1986, U., 1986. Increasing community recycling with persuasive communication and public commitment. J. Appl. Soc. Psychol. 16, 29-41.

City of Melbourne, 2014. High Rise Recycling Project. City of Melbourne, Melbourne. 
Connett, P., 2013. The Zero Waste Solution: Untrashing the Planet One Community at a Time. Chelsea Green Publishing, Vermont.

Dai, Y.C., Gordon, M.P.R., Ye, J.Y., Xu, D.Y., Lin, Z.Y., Robinson, N.K.L., Woodard, R., Harder, M.K., 2015. Why doorstepping can increase household waste recycling. Resour. Conserv. Recycl. 102, 9-19. https://doi.org/10.1016/j.resconrec.2015.06.004

Defra, 2007. Waste Strategy for England 2007. UK Department for Environment, Food and Rural Affairs (Defra).

Defra, 2006. Helping People Make Better Choices, in: Changing Behaviour through Policy Making. UK Department for Environment, Food and Rural Affairs (Defra) Sustainable development unit.

Defra, 2005a. A Practice Guide for the Development of Municipal Waste Management Strategies, Waste Management. UK Department for Environment, Food and Rural Affairs (Defra).

Defra, 2005b. Involving Communities and Stakeholders, Information Sheet 1, A Practice Guide for the Development of Municipal Waste Management Strategies. UK Department for Environment, Food and Rural Affairs (Defra).

Djerf, J.N.-, 1999. MEASURING THE SOCIAL FACTORS OF INTEGRATED WASTE MANAGEMENT A Case Study of Nine European Waste Management Programmes. Lund University.

Dolan, P., Hallsworth, M., Halpern, D., King, D., Vlaev, I., 2010. MINDSPACE: Influencing behaviour through public policy. Institute for Government and the Cabinet Office.

Dri, M., Canfora, P., Antonopoulos, I.S., Gaudillat, G., 2018. Best environmental management practice for the waste management sector, JRC SCIENCE FOR POLICY REPORT. European Union, Luxembourg. https://doi.org/10.2760/50247

du Toit, J., Wagner, C., Fletcher, L., 2017. Socio-spatial factors affecting household recycling in townhouses in Pretoria, South Africa. Sustainability 9. https://doi.org/10.3390/su9112033

Duffy, S., Verges, M., 2009. It Matters a Hole Lot. Environ. Behav. 41, 741-749. https://doi.org/10.1177/0013916508323737

Dupré, M., Meineri, S., 2016. Increasing recycling through displaying feedback and social comparative feedback. J. Environ. Psychol. 48, 101-107. https://doi.org/10.1016/j.jenvp.2016.07.004

EC, 2015. Comunication from the Commission to the European Parliament, the Council, the European Economic and Social Committee and the Committee of the Regions, Closing the loop - An EU action plan for the Circular Economy, COM (2015) 614 final. European Commission (EC), Brussels/BE.

Ekere, W., Mugisha, J., Drake, L., 2009. Factors influencing waste separation and utilization among households in the Lake Victoria crescent, Uganda. Waste Manag. 29, 3047-3051. https://doi.org/10.1016/j.wasman.2009.08.001

EU, 2008. Directive 2008/98/EC of the European Parliament and of the Council of 19 November 2008 on waste and repealing certain directives, Official Journal of the European Union. The European Parliament and the Council of the European Union (EU).

GAO, 2006. Additional Efforts Could Increase Municipal Recycling. United States Government Accountability Office (GAO).

Garnett, K., Cooper, T., 2014. Effective dialogue: Enhanced public engagement as a legitimising tool for municipal waste management decision-making. Waste Manag. 34, 2709-2726. https://doi.org/10.1016/j.wasman.2014.08.011

GMWDA, n.d. LIFE+ Up and Forward Project: Handbook, A Six Step Approach - Processes for targeting waste communication in low performing Urban Areas. Greater Manchester Waste Disposal Authority (GMWDA), Manchester.

Greenfield, D., 2016. Social, Environmental \&amp; Economic Solutions (SOENECS) Ltd Report for the London Waste and Recycling Board (LWARB) and the Greater London Authority (GLA) INTERNATIONAL RECYCLING RATE COMPARISON PROJECT. LWARB/SOENECS.

Guerin, D., Crete, J., Mercier, J., 2001. A multilevel analysis of the determinants of recycling behavior in the european countries. Soc. Sci. Res. 30, 195-218. https://doi.org/10.1006/ssre.2000.0694

Hage, O., Söderholm, P., Berglund, C., 2009. Norms and economic motivation in household recycling: Empirical evidence from Sweden. Resour. Conserv. Recycl. 53, 155-165. https://doi.org/10.1016/j.resconrec.2008.11.003

Hoornweg, D., Bhada-Tata, P., 2012. What A Waste. The World Bank.

Iyer, E.S., Kashyap, R.K., 2007. Consumer recycling: Role of incentives, information, and social class. J. Consum. Behav. 6, 32-47. https://doi.org/10.1002/cb

Jenkins, R.R., Martinez, S.A., Palmer, K., Podolsky, M.J., 2003. The determinants of household recycling: A materialspecific analysis of recycling program features and unit pricing. J. Environ. Econ. Manage. 45, 294-318. https://doi.org/10.1016/S0095-0696(02)00054-2

Jesson, J.K., Pocock, R.L., Stone, I., 2014. Barriers to recycling : A review of evidence since 2008. Waste \& Resources 
Action Programme (WRAP), Birmingham.

Kessler, T., Fritsche, I., 2018. Sozialpsychologie: Eine Einführung, in: Sozialpsychologie. Springer Fachmedien Wiesbaden, Wiesbaden, pp. 1-9. https://doi.org/10.1007/978-3-531-93436-5_1

Klöckner, C.A., Oppedal, I.O., 2011. General vs. domain specific recycling behaviour - Applying a multilevel comprehensive action determination model to recycling in Norwegian student homes. Resour. Conserv. Recycl. 55, 463-471. https://doi.org/10.1016/j.resconrec.2010.12.009

Knussen, C., Yule, F., 2008. "I'm not in the habit of recycling": The role of habitual behavior in the disposal of household waste. Environ. Behav. 40, 683-702. https://doi.org/10.1177/0013916507307527

Kurian, J., 2006. Stakeholder participation for sustainable waste management. Habitat Int. 30, 863-871. https://doi.org/10.1016/j.habitatint.2005.09.009

Li, C.J., Huang, Y.Y., Harder, M.K., 2017. Incentives for food waste diversion: Exploration of a long term successful Chinese city residential scheme. J. Clean. Prod. 156, 491-499. https://doi.org/10.1016/j.jclepro.2017.03.198

Loan, L.T.T., Nomura, H., Takahashi, Y., Yabe, M., 2017. Psychological driving forces behind households' behaviors toward municipal organic waste separation at source in Vietnam: a structural equation modeling approach. J. Mater. Cycles Waste Manag. 19, 1052-1060. https://doi.org/10.1007/s10163-017-0587-3

Ma, J., Hipel, K.W., 2016. Exploring social dimensions of municipal solid waste management around the globe $-\mathrm{A}$ systematic literature review. Waste Manag. 56, 3-12. https://doi.org/10.1016/j.wasman.2016.06.041

Ma, J., Hipel, K.W., Hanson, M.L., Cai, X., Liu, Y., 2018. An analysis of influencing factors on municipal solid waste source-separated collection behavior in Guilin, China by Using the Theory of Planned Behavior. Sustain. Cities Soc. 37, 336-343. https://doi.org/10.1016/j.scs.2017.11.037

Martin, M., Williams, I.D., Clark, M., 2006. Social, cultural and structural influences on household waste recycling: A case study. Resour. Conserv. Recycl. 48, 357-395. https://doi.org/10.1016/j.resconrec.2005.09.005

Matsumoto, T., 2012. Compact city policies: a comparative assessment, in: ISOCARP Congress 2011. p. 18. https://doi.org/10.1787/9789264167865-en

Matthies, E., Selge, S., Klöckner, C.A., 2012. The role of parental behaviour for the development of behaviour specific environmental norms - The example of recycling and re-use behaviour. J. Environ. Psychol. 32, $277-284$. https://doi.org/10.1016/j.jenvp.2012.04.003

McKenzie-Mohr, D., 2000. Promoting Sustainable Behavior : An Introduction to Community-Based Social Marketing. J. Soc. Issues 56, 543-554.

Meng, X., Wen, Z., Qian, Y., 2016. Multi-agent based simulation for household solid waste recycling behavior. Resour. Conserv. Recycl. 128, 535-545. https://doi.org/10.1016/j.resconrec.2016.09.033

Miafodzyeva, S., 2012. Understanding the Recycling Behaviour of Householders in Multicultural Urban Areas: Case Study Järva, Stockholm. KTH Royal Institute of Technology.

Miafodzyeva, S., Brandt, N., 2013. Recycling behaviour among householders: Synthesizing determinants via a metaanalysis. Waste and Biomass Valorization 4, 221-235. https://doi.org/10.1007/s12649-012-9144-4

Miliute, J., Plepys, A., 2009. Driving forces for high household waste recycling: Lessons from Sweden. Environ. Res. Eng. Manag. 1, 50-62.

Nomura, H., John, P.C., Cotterill, S., 2011. The use of feedback to enhance environmental outcomes: A randomised controlled trial of a food waste scheme, Paper to be presented at the Political Studies Association Conference, Edinburgh, 29 March - 1 April 2010. For the panel: Experimental research in political science: confronting the practical, methodological and ethical challenges. https://doi.org/10.1080/13549839.2011.586026

Oblad, E., 2018. The Story of Ljubljana, Case Study \#5. Zero Waste Europe.

Ölander, F., Thøgersen, J., 2005. The A-B-C of recycling. Eur. Adv. Consum. Res. 7, 297-302.

Park, S., 2018. Factors influencing the recycling rate under the volume-based waste fee system in South Korea. Waste Manag. 74, 43-51. https://doi.org/10.1016/j.wasman.2018.01.008

Park, S., Lah, T.J., 2015. Analyzing the success of the volume-based waste fee system in South Korea. Waste Manag. 43, 533-538. https://doi.org/10.1016/j.wasman.2015.06.011

Pettifor, H., 2012. Patterns of Household Practice, An Examination into the Relationship between Housework and Waste Separation for Households in the United Kingdom. Institute for Social \& Economic Research (ISER).

Pickin, J., Randell, P., 2017. Australian National Waste Report 2016. Department of the Environment and Energy \& Blue Environment Pty Ltd.

Puyuelo, B., Colón, J., Martín, P., Sánchez, A., 2013. Comparison of compostable bags and aerated bins with conventional storage systems to collect the organic fraction of municipal solid waste from homes. A Catalonia case study. Waste Manag. 33, 1381-1389. https://doi.org/10.1016/j.wasman.2013.02.015

R4R, 2014a. Final report on good practices. Regions for Recycling (R4R). 
R4R, 2014b. GOOD PRACTICE TALLINN: WASTE AWARENESS EDUCATIONAL CAMPAIGNS FOR CHILDREN AND ADULTS. Regions for Recycling (R4R).

Reichenbach, J., 2008. Status and prospects of pay-as-you-throw in Europe - A review of pilot research and implementation studies. Waste Manag. 28, 2809-2814. https://doi.org/10.1016/j.wasman.2008.07.008

Rompf, S.A., 2014. System Trust and Cooperation: The Case of Recycling Behavior. Munich Pers. RePEc Arch. 60279.

Saphores, J.M., Nixon, H., Ogunseitan, O.A., Shapiro, A.A., 2006. Household willingness to recycle electronic waste An Application to California. Environ. Behav. 38 (2).

Schwab, N., Harton, H.C., Cullum, J.G., 2014. The Effects of Emergent Norms and Attitudes on Recycling Behavior. Environ. Behav. 46, 403-422. https://doi.org/10.1177/0013916512466093

Schwartz, S.H., 1977. Normative influences on altruism. Adv. Exp. Soc. Psychol. 10, 221-279. https://doi.org/10.1016/S0065-2601(08)60358-5

Seyring, N., Dollhofer, M., Weißenbacher, J., Herczeg, M., McKinnon, D., Bakas, I., 2015. European Commission DG ENV, Brussels Assessment of separate collection schemes in the 28 capitals of the EU. BiPRO and the Copenhagen Resource Institute (CRI).

SF Environment, 2009. Mandatory Recycling and Composting Ordinance No. 100-09. San Francisco.

SF Environment, 2003. Resolution Setting Zero Waste Date 3700.

Shi, X., Thanos, A.E., Celik, N., 2014. Multi-objective agent-based modeling of single-stream recycling programs. Resour. Conserv. Recycl. 92, 190-205. https://doi.org/10.1016/j.resconrec.2014.07.002

Shrum, L.J., Lowrey, T.M., McCarty, J.A., 1994. Recycling as a marketing problem: A framework for strategy development. Psychol. Mark. 11, 393-416. https://doi.org/10.1002/mar.4220110407

Simon, J.M., 2018. The story of Contarina, Case Study \#4. Zero Waste Europe.

Southerton, D., McMeekin, A., Evans, D., 2011. International Review of Behaviour Change Initiatives, Social Research. The Scottish Government.

Stern, P.C., 2000. New Environmental Theories: Toward a Coherent Theory of Environmentally Significant Behavior. J. Soc. Issues 56, 407-424. https://doi.org/10.1111/0022-4537.00175

Thomas, C., 2001. Public understanding and its effects on recycling performance in Hampshire and Milton Keynes. Resour. Conserv. Recycl. 32, 259-274. https://doi.org/10.1016/S0921-3449(01)00065-9

Thomas, C., Sharp, V., 2013. Understanding the normalisation of recycling behaviour and its implications for other proenvironmental behaviours: A review of social norms and recycling. Resour. Conserv. Recycl. 79, 11-20. https://doi.org/10.1016/j.resconrec.2013.04.010

Timlett, R., Williams, I.D., 2011. The ISB model (infrastructure, service, behaviour): A tool for waste practitioners. Waste Manag. 31, 1381-1392. https://doi.org/10.1016/j.wasman.2010.12.010

Timlett, R.E., Williams, I.D., 2009. The impact of transient populations on recycling behaviour in a densely populated urban environment. Resour. Conserv. Recycl. 53, 498-506. https://doi.org/10.1016/j.resconrec.2009.03.010

Timlett, R.E., Williams, I.D., 2008. Public participation and recycling performance in England: A comparison of tools for behaviour change. Resour. Conserv. Recycl. 52, 622-634. https://doi.org/10.1016/j.resconrec.2007.08.003

Tonglet, M., Phillips, P.S., Read, A.D., 2004. Using the Theory of Planned Behaviour to investigate the determinants of recycling behaviour: A case study from Brixworth, UK. Resour. Conserv. Recycl. 41, 191-214. https://doi.org/10.1016/j.resconrec.2003.11.001

Tsaur, R.C., 2014. Analysis of the relationships among motivation to recycle, willingness to recycle, and satisfaction with recovery stations in Taiwan. WSEAS Trans. Environ. Dev. 10, $26-34$.

UN-HABITAT, 2010. Solid waste management in the world's cities, Water and Sanitation in the World's Cities 2010. United Nations Human Settlements Programme (UN-HABITAT).

UN DESA, 2018. 68\% of the World Population Projected To Live in Urban Areas By 2050. United Nations Department of Economic and Social Affairs (UN DESA).

UN DESA, 2017. World Population Prospects The 2017 Revision Key Findings and Advance Tables. United Nations Department of Economic and Social Affairs (UN DESA). https://doi.org/10.1017/CBO9781107415324.004

UN DESA, 2013. World Economic and Social Survey 2013. United Nations Department of Economic and Social Affairs (UN DESA).

Varotto, A., Spagnolli, A., 2017. Psychological strategies to promote household recycling . A systematic review with meta-analysis of validated fi eld interventions. J. Environ. Psychol. 51, 168-188. https://doi.org/10.1016/j.jenvp.2017.03.011

Vassanadumrongdee, S., Kittipongvises, S., 2018. Factors influencing source separation intention and willingness to pay for improving waste management in Bangkok, Thailand. Sustain. Environ. Res. 28, 90-99. 
https://doi.org/10.1016/j.serj.2017.11.003

Vicente, P., Reis, E., 2008. Factors influencing households' participation in recycling. Waste Manag. Res. 26, $140-146$. https://doi.org/10.1177/0734242X07077371

Vicente, P., Reis, E., 2007. Segmenting households according to recycling attitudes in a Portuguese urban area. Resour. Conserv. Recycl. 52, 1-12. https://doi.org/10.1016/j.resconrec.2007.01.005

Wan, C., Shen, G.Q., Choi, S., 2017. Experiential and instrumental attitudes: Interaction effect of attitude and subjective norm on recycling intention. J. Environ. Psychol. 50, 69-79. https://doi.org/10.1016/j.jenvp.2017.02.006

Whishaw, I.Q., Bergdall, V., Kolb, B., 2006. Chapter 8 Analysis of Behavior in Laboratory Rats, in: The Laboratory Rat. pp. 191-218. https://doi.org/10.1016/B978-012074903-4/50011-X

WHO, 2017. Strategic communications framework for effective communications. World Heal. Organ. 3, 1-56. https://doi.org/10.1002/ejoc.201200111

Widdowson, S.J., Maunder, A., Read, A.., 2014. Household Recycling Incentives - Do They Work?, Proceedings of the 20th WasteCon Conference 6-10 October 2014. Somerset West, Cape Town.

Williams, I.D., Taylor, C., 2004. Maximising household waste recycling at civic amenity sites in Lancashire, England. Waste Manag. 24, 861-874. https://doi.org/10.1016/j.wasman.2004.02.002

Wilson, D.C., 2015. Global Waste Management Outlook. United Nations Environment Programme (UNEP).

Wood, W., Quinn, J.M., Kashy, D.A., 2002. Habits in everyday life: Thought, emotion, and action. J. Pers. Soc. Psychol. 83, 1281-1297. https://doi.org/10.1037/0022-3514.83.6.1281

Woodard, R., Firoozmand, F., Harder, M.K., 2000. The Use of Cash Vouchers To Incentivise Householders To Recycle. Proc. Waste 2006; Sustain. Waste Resour. Manag.

Xu, D.Y., Lin, Z.Y., Gordon, M.P.R., Robinson, N.K.L., Harder, M.K., 2016. Perceived key elements of a successful residential food waste sorting program in urban apartments: stakeholder views. J. Clean. Prod. 134, 362-370. https://doi.org/10.1016/j.jclepro.2015.12.107

Yau, Y., 2012. Stakeholder Engagement in Waste Recycling in a High-Rise Setting. Sustain. Dev. 20, $115-127$.

Zaman, A.U., 2015. A comprehensive review of the development of zero waste management: Lessons learned and guidelines. J. Clean. Prod. 91, 12-25. https://doi.org/10.1016/j.jclepro.2014.12.013

Zaman, A.U., Lehmann, S., 2011. Urban growth and waste management optimization towards "zero waste city." City, Cult. Soc. 2, 177-187. https://doi.org/10.1016/j.ccs.2011.11.007

Zhu, N., 2016. Impact of communication appeals on recycling behaviors among undergraduate students. Purdue University.

\section{ONLINE REFERENCES}

${ }^{1} \mathrm{I}$. Kottasová, "China trash ban is a global recycling wake up call", April 20, 2018. Available at: http://money.cnn.com/2018/04/20/news/china-trash-recycling-environment/index.html [last accessed June 17, 2018]

2 Sustainable Development Goals. Available at: https://sustainabledevelopment.un.org/sdgs [last accessed June 17, 2018]

${ }^{3}$ RECYCLING magazin, "bvse: Recycling braucht verbesserte Mülltrennung”, April 17, 2018. Available at: https://www.recyclingmagazin.de/2018/04/17/bvse-recycling-braucht-verbesserte-muelltrennung/ [last accessed June 17, 2018]

${ }^{4}$ Science Daily, "Making bins more convenient boosts recycling and composting rates", April 21, 2017. Available at: https://www.sciencedaily.com/releases/2017/04/170421123255.htm [last accessed June 17, 2018]

${ }^{5}$ Kersten Schüßler, NDR, “Goldgrube Müll”, 2012. Available at: http://www.spiegel.tv/videos/158216goldgrube-muell [last accessed June 17, 2018]

${ }^{6}$ P.G. Hansen, "what is nudging?", August 16, 2016. Available at: https://behavioralpolicy.org/what-isnudging/ [last accessed June 17, 2018]

${ }^{7}$ The Economist, "Nudge nudge, think think, The use of behavioural economics in public policy shows promise", March 24, 2012. Available at: https://www.economist.com/node/21551032 [last accessed June 17, 2018]

${ }^{8}$ Institute for Government, MINDSPACE Behavioural Economics, "How behavior change theory can help meet current policy challenges". Available at: https://www.instituteforgovernment.org.uk/our-work/policy-making/mindspacebehavioural-economics [last accessed June 17, 2018] 
${ }^{9}$ A. W. Sile, "Singapore government focuses on recycling, but residents fail to pay their part", November 14, 2016. Available at: https://www.cnbc.com/2016/11/14/singapore-government-focuses-on-recycling-but-residents-fail-to-playtheir-part.html [last accessed June 17, 2018]

${ }^{10}$ The Atlantic CityLab, "A Brief History of Household Recycling". Available at: https://www.citylab.com/citymakers-connections/recycling/ [last accessed June 17, 2018]

${ }^{11}$ Zero Waste Europe, Available at: https://zerowasteeurope.eu/

12 Zero Waste International Alliance, Available at: http://zwia.org/

${ }^{13}$ M. Vilella, "Zero Waste Cities: At The Forefront Of The Sustainable Development Goals Agenda", September 15, 2016. Available at: https://www.huffingtonpost.com/mariel-vilella/zero-waste-cities-atthe b 12029704.html [last accessed June 17, 2018]

${ }^{14}$ Assises Nationales Des Déchets, "Waste recycling in Austria: analysis of the success". http://assisesdechets.org/en/interviews/201-waste-recycling-in-austria-analysis-of-the-success-nikolaus-berlakovich

${ }^{15} \mathrm{D}$. Woodring, "Hong Kong's woeful recycling efforts a result of mistrust in the system and lack of http://www.scmp.com/comment/insight-opinion/article/1859345/hong-kongs-woeful-recycling-efforts-resultmistrust-system [last accessed June 17, 2018]

${ }^{16}$ V. Hamilton, "How 'Guantanamera' went from Cuban's unofficial anthem to a Swedish recycling jingle", March 24, 2016. Available at: https://www.pri.org/stories/2016-03-24/how-guantanamera-went-cubasunofficial-anthem-swedish-recycling-iingle [last accessed June 17, 2018]

17 Dabitch, "Pantamera - Idol 2014 Hit Song - (2014) 3:00 (Sweden)", November 3, 2014. Available at: https://adland.tv/commercials/pantamera-idol-2014-hit-song-2014-300-sweden [last accessed June 17, 2018]

${ }^{18}$ Keep Britain Tidy, "Supporting Waste and Recycling Service Changes". Available at: http://www.keepbritaintidy.org/sites/default/files/resource/Supporting\%20waste\%20\%26\%20recycling\%20ser vice\%20changes.pdf [last accessed June 17, 2018]

${ }^{19}$ Greater Manchester Waste Disposal Authority (GMWDA), Up and Forward Project Review Document, 2015. Available at: https://www.cornerstonedm.co.uk/clients/GMWDA/GMWDA-Review-Brochure/GMWDAProject-Brochure.html\#p=1 [last accessed June 17, 2018]

${ }^{20}$ L. Dillon, "14 Ways to Improve Community Recycling Rates", January 1, 2015. Available at:

http://blog.bigbelly.com/14-ways-to-improve-community-recycling-rates [last accessed June 17, 2018]

${ }^{21}$ R. Bressa, "Recycling, Milan is one of the best cities in Europe for garbage disposal", September 15, 2016. Available at: https://www.lifegate.com/people/news/recycling-milan-europe

[last accessed June 17, 2018]

${ }^{22}$ See 19.

${ }^{23}$ See 20.

24 See 7.

${ }^{25}$ See 19.

${ }^{26}$ S. Eberlein/Alternet, "Where No City Has Gone Before: San Francisco Will Be World's First Zero-Waste Town by 2020", April 18, 2012. Available at:

https://www.alternet.org/story/155039/where no city has gone before\%3A san francisco will be world's first zero-waste town by 2020 [last accessed June 17, 2018]

${ }^{27}$ Keep Britain Tidy, "Staff Provision and Training". Available at: http://www.keepbritaintidy.org/sites/default/files/resource/Staff\%20Provision\%20and\%20Training.pdf [last accessed June 17, 2018]

${ }^{28}$ Keep Britain Tidy, Available at: http://www.keepbritaintidy.org/

${ }^{29}$ City of Austin, Available at: http://www.austintexas.gov/department/single-stream-recycling [last accessed June 17, 2018]

${ }^{30} \mathrm{G}$. Bakshi, "Taiwan has one of the world's most efficient recycling systems", May 19, 2016. Available at: https://www.globalcitizen.org/en/content/taiwan-musical-garbage-trucks-recycling/ [last accessed June 17, 2018]

${ }^{31}$ See 26.

${ }^{32}$ E. Schumaker, "The Psychology Behind Why People Don't Recycle", August 3, 2016. Available at:

https://www.huffingtonpost.com/entry/psychology-of-why-people-dontrecycle us 57697a7be4b087b70be605b3?guccounter=1 [last accessed June 17, 2018] 
${ }^{33}$ See 20.

${ }^{34}$ Prügihunt, Available at: https://www.tallinn.ee/prygihunt/ [last accessed June 17, 2018]

${ }^{35}$ KIK Environmental Investment Centre, "Waste Wolf teaches people to sort waste". Available at:

https://www.kik.ee/en/success-story/waste-wolf-teaches-people-sort-waste [last accessed June 17, 2018]

${ }^{36} \mathrm{~J}$. Prisco, CNN, "Can psychology influence the way we recycle?", May18, 2017. Available at:

https://edition.cnn.com/2017/05/18/health/psychology-of-recycling/index.html [last accessed June 17, 2018]

${ }^{37}$ P. Griffiths, "Boost recycling? Try a little persuasion", November 15, 2007. Available at:

https://www.reuters.com/article/us-britain-persuasion/boost-recycling-try-a-little-persuasion-

idUSL1568112420071115 [last accessed June 17, 2018]

38 See 36.

${ }^{39}$ S. Goodyear, "Seattle Tries Shaming Its Citizens Into Participating in Composting", January 28, 2015. Available at: https://www.citylab.com/equity/2015/01/seattle-tries-shaming-its-citizens-into-participating-in-composting/384894/ [last accessed June 17, 2018]

${ }^{40} \mathrm{M}$. Dukmasova, "The truth about what happens when you recycle the wrong stuff in Chicago", July 13, 2017. Available at: https://www.chicagoreader.com/Bleader/archives/2017/07/13/the-truth-about-whathappens-when-you-recycle-the-wrong-stuff-in-chicago [last accessed June 17, 2018]

${ }^{41}$ See 39.

42 See 19.

${ }^{43}$ See 20.

${ }^{44}$ See 32.

${ }^{45}$ Edinburgh News, "Edinburgh recycling rates soar 85 per cent", January 5, 2015. Available at:

https://www.edinburghnews.scotsman.com/news/edinburgh-recycling-rates-soar-85-per-cent-1-3650917 [last accessed June 17, 2018]

${ }^{46}$ I. Gulland, Zero Waste Scotland, "Edinburgh 'nudging' success in recycling”, January 9, 2015. Available at: https://www.zerowastescotland.org.uk/content/edinburgh-\%E2\%80\%98nudging\%E2\%80\%99-successrecycling [last accessed June 17, 2018]

47 See 32.

${ }^{48}$ M. Buechler, "The landfill nudge at the University of Pennsylvania", September 13, 2011. Available at: http://nudges.org/tag/recycling/ [last accessed June 17, 2018]

${ }^{49}$ T. Szaky,"New labeling takes confusion out of recycling", July 2, 2014. Available at:

http://www.packagingdigest.com/sustainable-packaging/new-labeling-takes-confusion-out-recycling 140702 [last accessed June 17, 2018]

${ }^{50}$ Veolia UK, Plastics Recycling. Available at: https://www.veolia.co.uk/westberkshire/waste-services/wasteservices/recycling/plastics-recycling [last accessed June 17, 2018]

${ }^{51}$ M.T.G. Hock, "The National University of Singapore nudges", September 9, 2009. Available at: https://nudges.wordpress.com/2009/09/09/the-national-university-of-singapore-nudges/ [last accessed June 17, 2018]

52 B. Brassaw, "Germany: A Recycling Program That Actually Works", July 11, 2017. Available at: https://earth911.com/business-policy/recycling-in-germany/ [last accessed June 17, 2018]

${ }^{53}$ US Environmental Protection Agency (EPA), "Zero Waste Case Study: San Jose". Available at:

https://www.epa.gov/transforming-waste-tool/zero-waste-case-study-san-jose [last accessed June 17, 2018]

${ }^{54}$ SF Environment, Recycling \& Composting in San Francisco - Frequently Asked Questions (FAQ). Availa-

ble at: https://sfenvironment.org/recycling-composting-faqs\#what [last accessed June 17, 2018]

${ }^{55}$ See 26.

${ }^{56}$ K. Heinrich, "How San Francisco Achieved a High Performing Food Waste Composting Program", June 9, 2017. Available at: https://beyondfoodwaste.com/what-makes-san-franciscos-food-recycling-programsuccessful// [last accessed June 17, 2018]

${ }^{57}$ K. Chrobog, "South Korea: Cutting Back on Food Waste", November 12, 2015. Available at:http://pulitzercenter.org/reporting/south-korea-cutting-back-food-waste [last accessed June 17, 2018]

${ }^{58}$ G. Eduljee, "Have Recycling Rewards Scheme Had Their Chips?". Available at: https://ciwmjournal.co.uk/recycling-rewards-scheme-chips/ [last accessed June 17, 2018]

59 See 32. 
${ }^{60}$ M. Wollan, "San Francisco to Toughen a Strict Recycling Law", June 10, 2009. Available at: https://www.nytimes.com/2009/06/11/us/11recycle.html? r=0 [last accessed June 17, 2018]

${ }^{61}$ See 39.

62 K. Capps, "Every City Needs Vancouver's Ban on Food Scraps", January 14, 2015. Available at: https://www.citylab.com/solutions/2015/01/every-city-needs-vancouvers-ban-on-food-scraps/384391/ [last accessed June 17, 2018]

${ }^{63}$ City of Woodbury, Trash \& Recycling. Available at: http://www.woodbury.nj.us/city-departments/public-worksdepartment/trash-recycling [last accessed June 17, 2018]

${ }^{64}$ See 30.

${ }^{65}$ Available at: https://www.recyclebank.com/

${ }^{66}$ L. Evans, "As cities shift strategies, so does Recyclebank", October 25, 2016. Available at: https://resource-recycling.com/recycling/2016/10/25/as-cities-shift-strategies-so-does-recyclebank/ [last accessed June 17, 2018]

${ }^{67}$ amsterdam city, "De Gezonde Stad (Healthy City) opens first Zero Waste Lab in the Netherlands: a neighbourhood lab for social \& circular innovation", 2016. Available at:

https://amsterdamsmartcity.com/projects/eerste-zero-waste-lab-in-nederland [last accessed June 17, 2018]

$68 \mathrm{~J}$. Clasper, "'Trash for food': the Mexico City market that's tackling the capital's waste problem",

April 25, 2016. Available at: https://www.virgin.com/virgin-unite/trash-food-mexico-city-market-thats-tacklingcapitals-waste-problem [last accessed June 17, 2018]

69 See 32.

${ }^{70}$ G. Monbiot, "Sustainable cities must be compact and high-density", June 30, 2011. Available at:

https://www.theguardian.com/environment/georgemonbiot/2011/jun/30/sustainable-cities-urban-planning [last accessed June 17, 2018]

${ }^{71}$ D. Fell for the Guardian Professional Network, "Why waste is still a built environment concern for sustainable cities", May 8, 2012. Available at: https://www.theguardian.com/sustainable-business/waste-built-

environment-sustainable-cities [last accessed June 17, 2018]

72 See 19.

${ }^{73}$ See 54.

${ }^{74}$ The Chicago Recycling Ordinance. Available at:

https://www.recyclebycity.com/downloads/commerical ordinance.pdf [last accessed June 17, 2018]

75 See 40.

${ }^{76}$ S. Eminton, "Milan - lessons from a large city", December 12, 2016. Available at:

https://www.letsrecycle.com/news/latest-news/milan-lessons-from-a-large-city/ [last accessed June 17, 2018]

77 S. Boh, "Sorting out the recycling blues of Singapore", June 30,2016. Available at:

https://www.straitstimes.com/opinion/sorting-out-the-recycling-blues-of-singapore [last accessed June 17, 2018]

${ }^{78}$ See 56. 